\title{
Controls and limits on bedrock channel geometry
}

\author{
Brian J. Yanites ${ }^{1,2}$ and Gregory E. Tucker ${ }^{1,3}$ \\ Received 16 November 2009; revised 21 June 2010; accepted 16 July 2010; published 10 November 2010.
}

[1] Data on channel geometry in naturally incising bedrock rivers reveal variable relationships between channel width, slope, and erosion rate. To explain the range of relationships between these parameters, we propose an optimized channel geometry model. The model reproduces previous theoretical and numerical modeling scaling relationships; however, to explain the field data, the model must incorporate the effects of immobile sediment cover that reduces vertical incision efficiency. Adding sediment to a system for a given rate of base level fall both widens and steepens the channel. We also find that a constant width to depth ratio is only valid for streams where the shear stress required for sediment transport is insignificant compared to the shear required to erode at the imposed base level fall. Our model offers an explanation of seemingly contradictory field observations of controls on channel width and shows that channel width fundamentally controls the erosive potential of a river especially when it carries a significant bed load.

Citation: Yanites, B. J., and G. E. Tucker (2010), Controls and limits on bedrock channel geometry, J. Geophys. Res., 115, F04019, doi:10.1029/2009JF001601.

\section{Introduction}

[2] The width of river channels exerts an important control on the rates of bedrock incision and landscape dissection, and yet the factors that control the shape and size of bedrock channels are not well understood. Relationships among channel width, erosion rate, and channel slope in actively incising rivers show different patterns in different settings [Duvall et al., 2004; Finnegan et al., 2008; Lavé and Avouac, 2001; Snyder et al., 2003; Whipple, 2004; Amos and Burbank, 2007; Whittaker et al., 2007a; Wohl and David, 2008]. For example, Lavé and Avouac [2001] report that channel width is strongly correlated (inversely) with incision rate in the Sub and Lesser Himalaya of central Nepal. Slope, on the other hand, varies relatively little, and in the case of one river, remains essentially constant across a tenfold variation in incision rate. By contrast, data from small $\left(\sim<20 \mathrm{~km}^{2}\right)$, steep $(8-30 \%)$ catchments in the Mendocino triple junction area of northern California show no statistical difference in channel width between basins undergoing an eightfold difference in erosion rate with a twofold difference in channel slope [Snyder et al., 2003]. Currently, no study has accounted for these variable relationships among width, slope, and incision rate in bedrock river channels. Understanding the origin and diversity of observed relationships is necessary to fully appreciate the controls and limits of bedrock channel

\footnotetext{
${ }^{1}$ Department of Geological Sciences, University of Colorado at Boulder, Boulder, Colorado, USA.

${ }^{2}$ Now at Department of Geological Sciences, University of Michigan, Ann Arbor, Michigan, USA.

${ }^{3}$ CIRES, University of Colorado at Boulder, Boulder, Colorado, USA.

Copyright 2010 by the American Geophysical Union. 0148-0227/10/2009JF001601
}

morphology and dynamics. Such an understanding would help advance techniques of deducing tectonic rates from topography [e.g., Wobus et al., 2006a], improve models of landscape evolution [e.g., Tucker, 2004], and better quantify the feedbacks between mountain building and climate processes [e.g., Roe et al., 2008]. This paper aims to unravel the origins of observed width-slope-erosion rate relationships in actively incising bedrock river channels. Specifically, we explore the role of channel width as a potentially important control on the erosive potential in many bedrock river systems [e.g., Finnegan et al., 2005; Lavé and Avouac, 2001; Stark, 2006; Turowski et al., 2008; Whittaker et al., 2007a; Yanites et al., 2010].

[3] Mathematical models of river incision often use an empirical approximation that fixes channel width solely as a function of water discharge [DeLong et al., 2007; Roe et al., 2002; Whipple and Tucker, 1999; Willett, 1999]. This is based on data sets that show a strong correlation between width and discharge, both for alluvial rivers [Leopold and Maddock, 1953] and bedrock rivers [Montgomery and Gran, 2001; Whittaker et al., 2007b]. Yet in many rivers, channel width narrows in zones of enhanced erosion rate. Such narrowing acts to increase the boundary shear stress on the bed and the erosion potential of the river [Duvall et al., 2004; Finnegan et al., 2008; Lavé and Avouac, 2001; Whittaker et al., 2007a; Yanites et al., 2010]. Recent theoretical and modeling work has suggested that the channel width-depth ratio tends to be constant in a homogeneous substrate with no sediment cover [Finnegan et al., 2005; Wobus et al., 2006b]; however, while some field data appear consistent with a constant width-depth ratio [Finnegan et al., 2005], other evidence suggests that this is not always the case [Amos and Burbank, 2007; Turowski et al., 2007; Whittaker et al., 2007b; Turowski et al., 2009; Yanites et al., 2010]. 


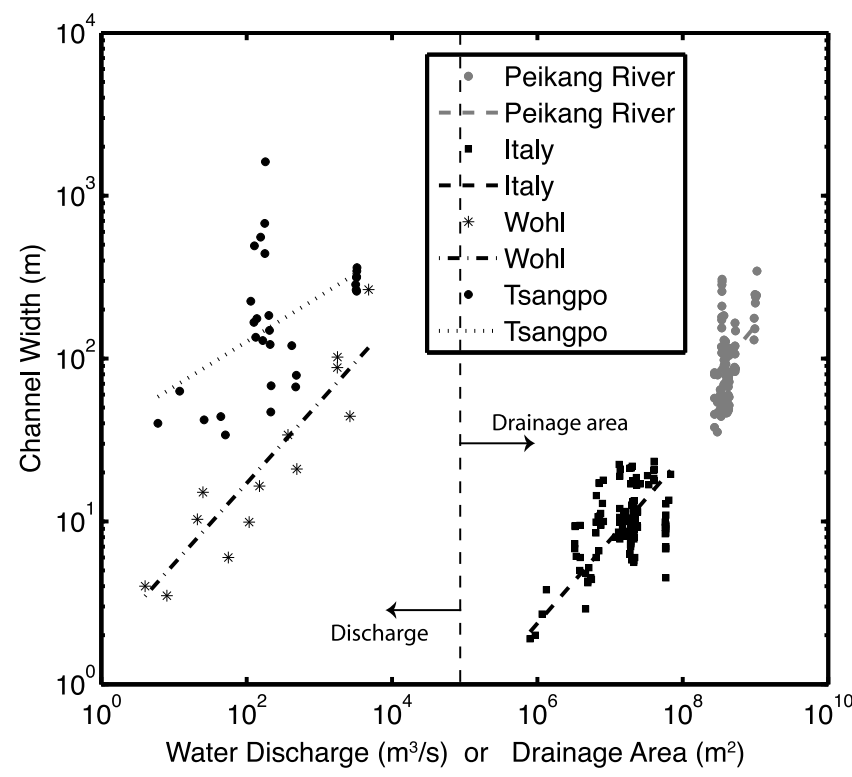

Figure 1. Channel width versus water discharge and drainage area. Discharge is reported for Tsangpo Gorge [Finnegan et al., 2008] and for the data of Wohl and David [2008]. Drainage area is used for Italy and the Peikang River. The scaling coefficients and exponents (Table 1) are used to normalize channel width.

Laboratory-scale experimental work has shown that channels narrow with increasing rock-uplift rate [Turowski et al., 2006]. Finally, flume work has shown that width is positively correlated with sediment flux [Finnegan et al., 2007; Johnson and Whipple, 2007].

[4] To explain these seemingly conflicting observations, we explore the implications of an optimized channel geometry model that accounts for variation in water discharge, sediment supply, and base level fall. Optimized channel geometry models have a long history in alluvial river geomorphology [Kirkby, 1977; Chang, 1979; Nanson and Huang, 2008] and have also been applied to bedrock channels [Turowski et al., 2007]. We build on this previous work and treat channel width and slope as interdependent variables that adjust to the three environmental variables listed above. As discussed below, the geometry model is based on recent studies that suggest a natural tendency for width and slope to evolve toward an equilibrium configuration in which slope is minimized for a given shear stress and erosion rate. The analysis addresses the following questions: Why do some places show strong, inverse relationships between width and either slope or erosion rate, but others do not? Why is the width to depth ratio constant in some places, but varies inversely with slope or incision rate in others? Are power law scaling relationships among width, slope, and erosion rates in bedrock rivers always appropriate?

[5] We begin by presenting published examples of bedrock channel width, depth, slope, and erosion rate. Next, we explain the framework of a model based on boundary shear stress optimization that includes the effects of reducing fluvial incision efficiency with immobile sediment cover. We then discuss model results that explain the controls and limits of our model's predicted channel geometry. Finally, we dis- cuss some key points of the field data in light of insight from the theoretical work.

\section{Field Data}

[6] We organized and analyzed data from eight studies of bedrock rivers. The data cover a range of observations reported for channel width, slope, drainage area or discharge, and in some cases the rate of erosion. This broad data set illustrates the range of field-observable correlations with channel width (Figures 1-3).

\subsection{Santa Ynez, California}

[7] Duvall et al. [2004] measured channel width and slope for the Santa Ynez Mountains in Southern California from field surveys and DEM analysis. Elevated marine terraces dated by a number of geochronometers and an assumption of steady state with respect to rock uplift provide them with estimates of incision rate. Rates of rock uplift range from $\sim 0.75 \mathrm{~mm} / \mathrm{yr}$ in the west to $\sim 5 \mathrm{~mm} / \mathrm{yr}$ in the southeast part of the range. The bedrock channels incising the Santa Ynez are described as being characterized by a mix of predominately bedrock bed reaches and reaches mantled by a thin and scattered blanket of coarse sediment.

\subsection{Peikang River, Central Taiwan}

[8] We measured channel width in the field and slope from a $20 \mathrm{~m}$ digital elevation model for a $60 \mathrm{~km}$ reach of the Peikang River. Bedrock strath terraces dated with optically stimulated luminescence dating techniques constrain incision rate over a $\sim 30 \mathrm{~km}$ reach of river [Yanites et al., 2010]. The incision rates range from $\sim 1-2 \mathrm{~mm} / \mathrm{yr}$ in a reach of relatively slow incision to $\sim 6-10 \mathrm{~mm} / \mathrm{yr}$ just upstream of the Shuilikeng Fault [Yanites et al., 2010]. The rivers along this reach are currently mantled by coarse alluvium with a median grain size of $\sim 100 \mathrm{~mm}$.

\subsection{Central Nepal}

[9] Lavé and Avouac [2001] measured channel morphology in the Siwalik Hills in Nepal. They estimated channel width from satellite images and aerial photography to an accuracy of 10-20 m ( $1-20 \%$ of width values). Lavé and Avouac [2001] calculated slope from a $20 \mathrm{~m}$ DEM derived from SPOT imagery. Discharge was assumed constant for the Bayeka at $350 \mathrm{~m}^{3} / \mathrm{s}$ and for the Bagmati at $2000 \mathrm{~m}^{3} / \mathrm{s}$. We note that the confluence with the Marin River [Lavé and Avouac, 2000] may complicate this assumption for the Bagmati. They estimated incision rates from strath terraces dated with ${ }^{14} \mathrm{C}$. In the study reaches, the Bayeka and Bagmati rivers undergo a roughly fourteen-fold and tenfold increase in bedrock incision rate, respectively. An alluvial cover with median grain sizes of $49 \mathrm{~mm}$ for the Bayeka and $55 \mathrm{~mm}$ for the Bagmati dominates the channel bed.

\subsection{Central Italy}

[10] Channel width was measured in the field [Whittaker et al., 2007a, 2007b]. They estimated slope from a $20 \mathrm{~m}$ DEM and in the field. Data were collected along three rivers with different spatial and temporal incision histories. The Fosso Tascino crosses a horst block with a uniform rockuplift rate over the past $\sim 3$ Ma [Whittaker et al., 2007a, 


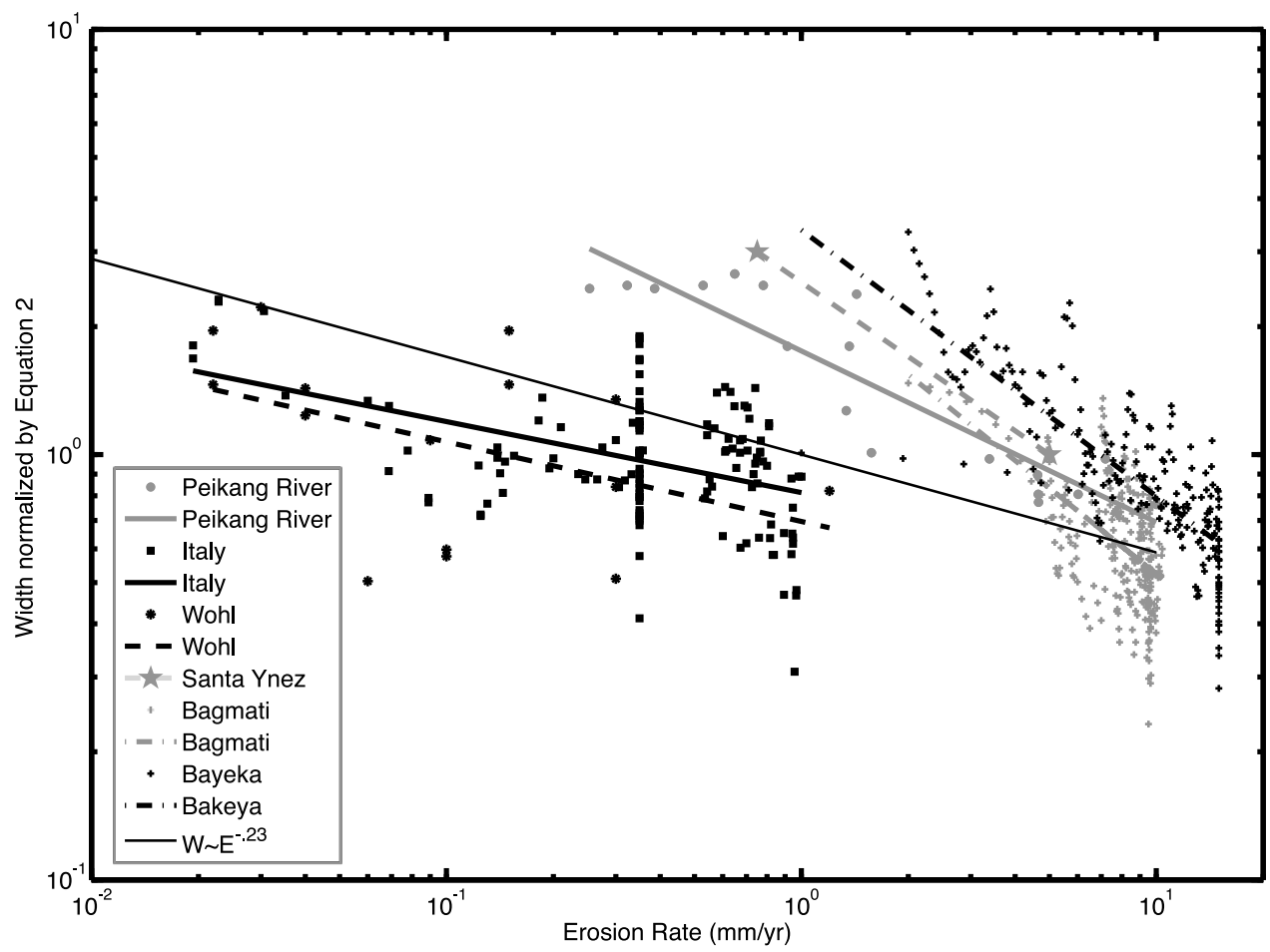

Figure 2. Reference channel width versus erosion rate for field data discussed in text. Thin, solid black line represents $W \sim E^{-0.23}$ [Wobus et al., 2006b].

2007b]. The data of Whittaker et al. [2007a, 2007b] suggest that the stream incision rate closely matches the relative base level fall rate of $\sim 0.35 \mathrm{~mm} / \mathrm{yr}$. The Valleluce River crosses a tilted normal fault block and thus rock-uplift rate decreases upstream. Assuming steady state, the river has a maximum of $\sim 0.3 \mathrm{~mm} / \mathrm{yr}$ incision rate at the fault that linearly decreases to $0 \mathrm{~mm} / \mathrm{yr} \sim 4 \mathrm{~km}$ upstream. The third river, the Rio Torto, is influenced by a recent ( $\sim 0.75 \mathrm{Ma})$ acceleration of rock-uplift

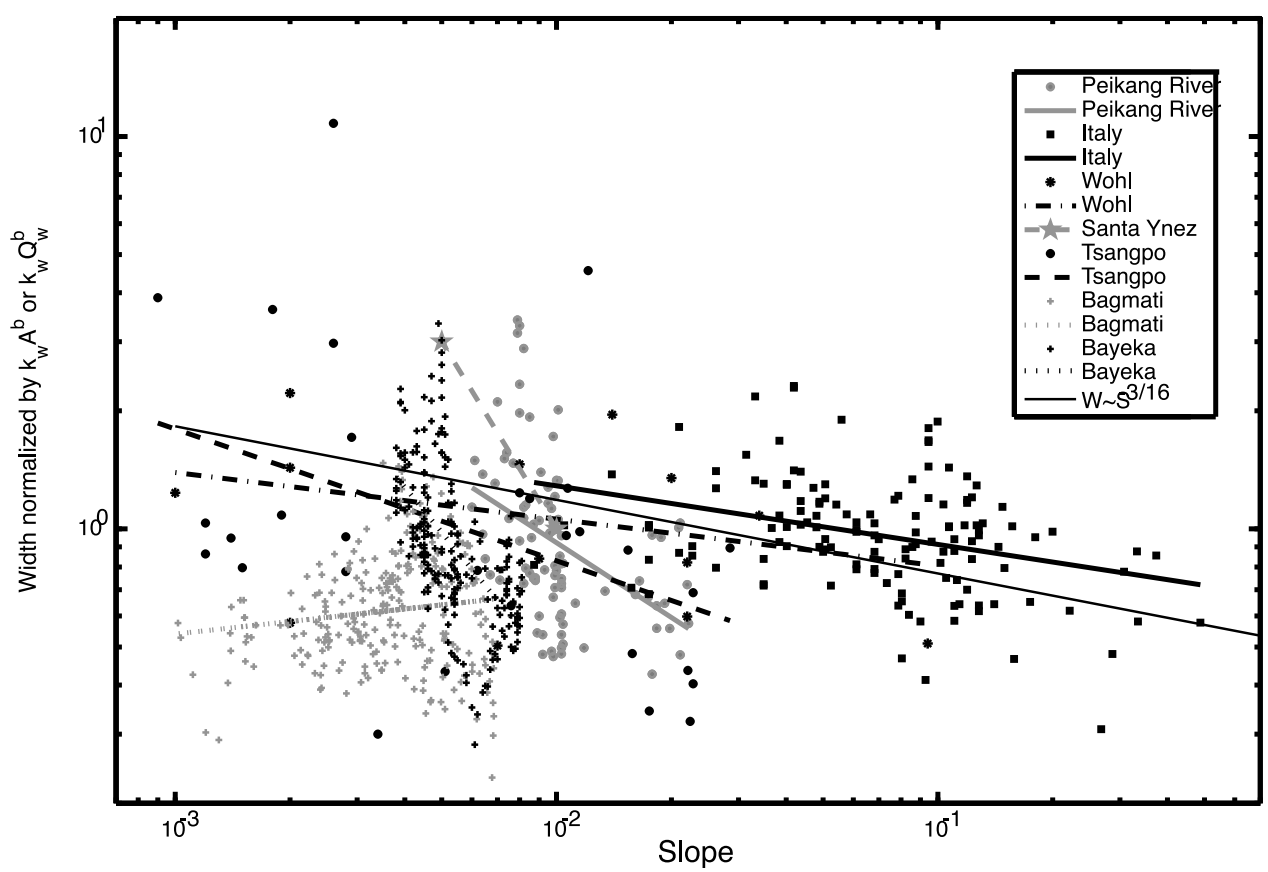

Figure 3. Reference channel width versus channel slope for published data. Thin, solid black line represents $W \sim S^{-3 / 16}$ for comparison to previous theoretical and numerical predictions [Finnegan et al., 2005; Wobus et al., 2006b]. 
rate causing a transient signal of erosion that has propagated about two kilometers upstream [Attal et al., 2008]. We choose the top of the convexity ( $\sim 3.5 \mathrm{~km}$ upstream from the fault) as the boundary between new and old incision rates. To estimate modern incision rates, we use the fault geometry and throwrate history reconstructed by Whittaker et al. [2007b] and Attal et al. [2008], and assume that the top of the convexity marks the boundary between an upper reach that has adjusted to an earlier maximum throw rate of $\sim 0.3 \mathrm{~mm} / \mathrm{yr}$, and a lower reach that has reequilibrated in response to accelerated fault motion (throw rate at the fault $\sim 1 \mathrm{~mm} / \mathrm{yr}$ ). When accounting for fault-block tilt, the estimated incision rates in the lower reach decline from $\sim 1 \mathrm{~mm} / \mathrm{yr}$ at the fault to $\sim 0.3 \mathrm{~mm} / \mathrm{yr}$ at the top of the convexity. Estimated incision rates along the upstream reach range from $0.18 \mathrm{~mm} / \mathrm{yr}$ just upstream of the convexity to $0.03 \mathrm{~mm} / \mathrm{yr}$ at the upstream end of the river (see Whittaker et al. [2007a, 2007b] and Attal et al. [2008] for details of the erosion-rate analysis).

\subsection{Global Data Set of Wohl and David [2008]}

[11] Wohl and David [2008] report measured channel width and slope data but do not report erosion rates, so we only selected data where other studies have reported erosion rates for the rivers in their data set (note we are assuming steady state erosion in each of these cases). Erosion in Panama was estimated with basin-wide cosmogenic radionuclide (CRN) concentrations [Nichols et al., 2003]. Erosion along the St. Vrain Creek in Colorado was assumed to equal that of Boulder Creek to the south, which was estimated using basin-wide CRNs by Dethier and Lazarus [2006] and CRN estimates of strath terrace ages [Schildgen et al., 2002]. In the eastern U.S., a suite of CRN applications near the river localities provide estimates of erosion rates [Granger et al., 1997; Reusser et al., 2004; Springer et al., 1997; Ward et al., 2005]. Mesolithic tools constrain the timing of incision into a gorge in southeast India [Wohl and Achyuthan, 2002]. The erosion rate on the Boso Peninsula in Japan was assumed to match the uplift rates reported by Wohl and Ikeda [1998]. Basin-wide CRN analysis gives estimates of erosion rates in the Rio Puerco in New Mexico [Bierman et al., 2001].

\subsection{Mendocino Triple Junction}

[12] Incision rate was estimated by assuming steady state with respect to rock uplift, which was calculated from vertically translated marine terraces [Snyder et al., 2003]. Values range from 0.5 to $4 \mathrm{~mm} / \mathrm{yr}$. We analyze the scaling relationships reported for two different zones, a high uplift zone and a low uplift zone. The channels are small (widths on the order of 5-20 m) and are described as a mix of bedrock, step-pool, and boulder cascade conditions.

\subsection{Other Data Sets}

[13] Finnegan et al. [2008] measured slope and width from digital elevation models and satellite imagery in the region of the Namche Barwa-Gyala Peri massif. They also estimated discharge by accounting for orographic effects and concluded that buffering by sediment cover strongly controls river incision in this region. We also briefly discuss the Clearwater River studied by Tomkin et al. [2003] and rivers in the San Gabriel Mountains discussed by Whipple [2004]. Neither of the latter two studies shows any definitive correlation between channel width and incision rate.

\subsection{Width Normalization}

[14] In all cases where data are available, width, $W$, correlates strongly with discharge, $Q$, and basin size, $A_{B}$, (Figure 1), and we removed these effects by first finding regression coefficients for the relationships

$$
\begin{gathered}
W=k_{w} A_{B}^{b} \\
W=k_{w q} Q^{b_{q}}
\end{gathered}
$$

We fit the data to find the values for $k_{w}, k_{w q}, b$, and $b_{q}$. We regressed channel width with peak annual discharge for the data set of Wohl and David [2008] and with mean annual discharge for the data of Finnegan et al. [2008] as both studies provided independent estimates of these values. Whittaker et al. [2007b] and Yanites et al. [2010] linearly scaled drainage area to calculate discharge estimates. We regressed channel width with drainage area for these studies. Then we normalize the measured channel width

$$
W^{*}=\frac{W_{m}}{k_{w} A_{B}^{b}}
$$

where $W_{m}$ is the measured channel width and $W^{*}$ is a nondimensional width. Note that $k_{w q}$ and $b_{q}$ are used in place of $k_{w}$ and $b$ if channel discharge is reported. We will refer to this normalized width as 'reference channel width' for the remainder of the article. If the original data set had regression coefficients from a broader data range, we used those published values. If not, we performed our own regressions. Channel width data from Lavé and Avouac [2001] were normalized by the mean width since a constant discharge was assumed along their reaches. The normalization allows various reaches to be compared to each other by removing the strong influence of discharge on channel width.

[15] We also calculate the channel width to depth ratio, or $W / H$, where the data are available in the literature. This gives an aspect ratio of cross-sectional channel geometry and provides a relative measurement of the proportion of boundary shear stress dissipated on the bed and walls.

\section{Results From Data Analysis}

\subsection{Width and Erosion Rate}

[16] The greatest sensitivity of reference channel width to incision rate occurs in Taiwan and the Himalayas (Figure 2 and Table 1). Lavé and Avouac [2001] found a strong correlation between channel width and incision rate for the Bagmati and Bayeka rivers in Nepal, but only one river (Bayeka) had a significant change in channel steepness as the rate of river incision increased by a factor of ten. A similar result is found by Yanites et al. [2010] along the middle Peikang River in central Taiwan, where along-stream variations in shear stress primarily reflect variations in width rather than gradient. Channel width in the global data set from Wohl and David [2008] appears to correlate (inversely) with ero- 
sion rate, although the relationship is not as steep. The data from Italy [Whittaker et al., 2007b] are confounded by a transient erosional signal in one of the basins but still appear to have an inverse correlation between channel width and erosion rate. Duvall et al. [2004] report that channels in the Santa Ynez Range are 3 times narrower in the high incision zone than in the low incision zone for a specified discharge. In the Mendocino triple junction region, northern California, Snyder et al. [2003] reported statistically indistinguishable scaling relationships (both the exponents and coefficients) between channel width and drainage area between basins incising at different rates $(0.5$ to $4 \mathrm{~mm} / \mathrm{yr})$ but significant (up to twofold) differences in area-normalized channel slope (calculated in a similar manner as our reference channel width in equation (2)) are present. Tomkin et al. [2003] report a scaling relationship between channel width and drainage area in the Clearwater River; however, a signal of decreasing incision rate in the downstream direction makes scaling relationships with incision rate difficult to discern. Whipple [2004] reports that channels in the San Gabriel Mountains in southern California do not exhibit significant changes in reference channel width along a known gradient in rock uplift, even though channel slope is significantly steeper in the rapid rock uplift reaches. Thus, while some data sets show a strong inverse correlation between width and incision rate, others show little or no correlation.

\subsection{Width and Slope}

[17] In most cases, reference channel width correlates inversely with channel slope (Figure 3). The steepness of the relationships, however, is quite variable. The steepest relationships occur in the Bayeka River of Nepal and the Peikang River of Taiwan. In the Bagmati River of Nepal, where Lavé and Avouac [2001] concluded that only channel width (not slope) adjusts to changes in rock-uplift rate, almost no correlation exists between channel width and slope. Data from the Tsangpo [Finnegan et al., 2008] show a strong (inverse) correlation between channel width and slope as do data from the Santa Ynez [Duvall et al., 2004]. Data from Wohl and David [2008] and from Italy [Whittaker et al., 2007b] have correlations between reference width and slope, but the slope of the regression is relatively low (Table 1). We do note some peculiarities in the data, such as that for the Peikang River and the Bakeya, which appear to be nonlinear in $\log$ - $\log$ space.

\subsection{Width to Depth Ratios}

[18] The $W / H$ ratio correlates with both slope and erosion rate (Figure 4). The Peikang River data appear to transition from a steep relationship for high values of $W / H$ ratio and lower slopes to a less steep relationship for lower values of $W / H$ and higher slopes. The $W / H$ ratios from Italy and the rivers of Wohl and David [2008] have a less steep relationship with slope. Although it is difficult to say for certain, the data from Italy and Taiwan appear to converge toward a constant $W / H$ ratio at relatively high values of slope. For example, the constant for Taiwan appears to be $\sim 12-18$, whereas for Italy this value is approximately six. $W / H$ ratios show a more complicated relationship with erosion rate. Data from Taiwan and from Wohl and David [2008] appear consistent with a power law scaling. The data from Italy, however, exhibit a poor correlation between $W / H$ ratio and erosion rate, although 

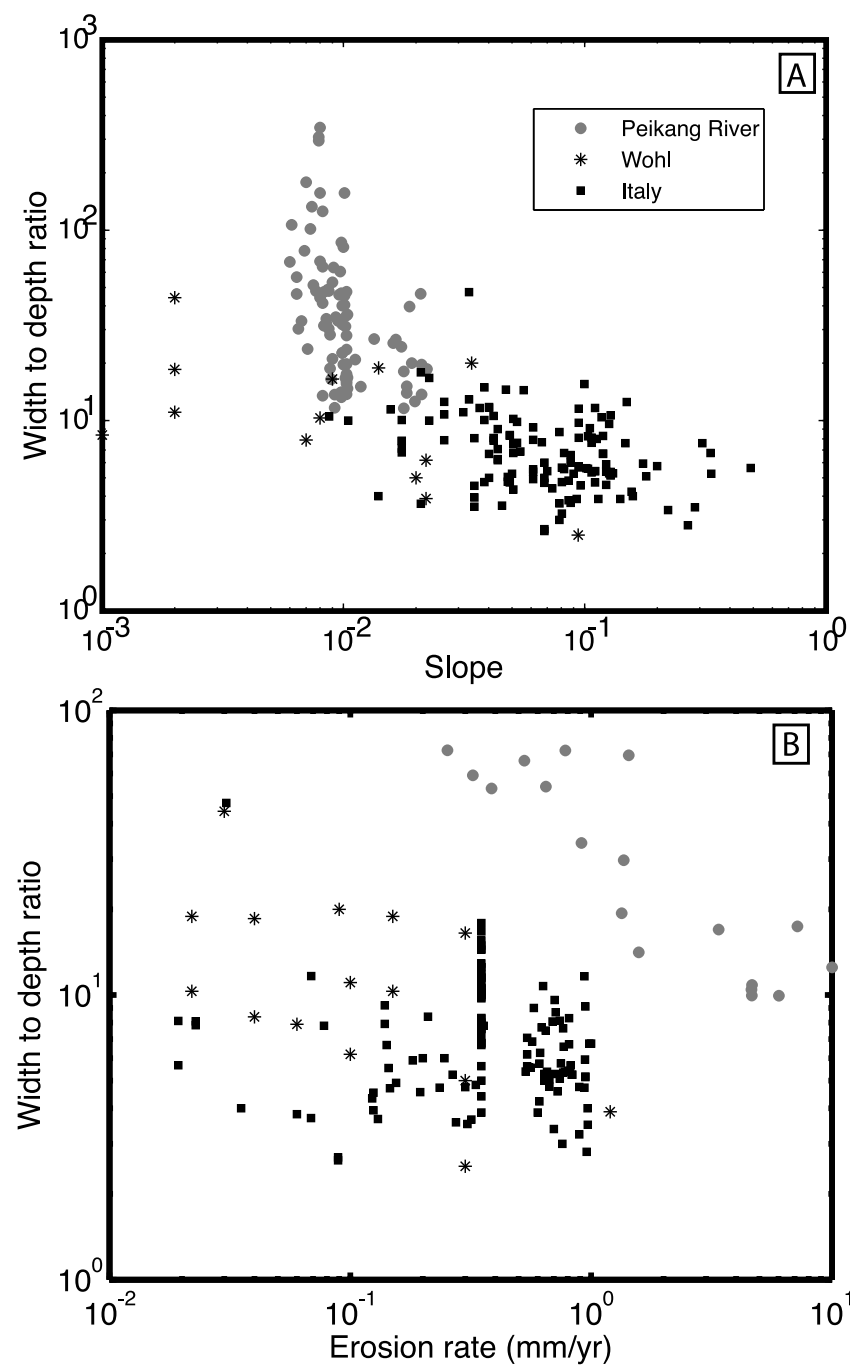

Figure 4. Channel width to depth $(W / H)$ ratio versus (a) slope and (b) erosion rate for published data in log-log space.

the slope of the trend appears similar to that of the data from Wohl and David [2008].

\subsection{Data Analysis Summary}

[19] The data reveal variable relationships between channel width and erosion rate. Whereas the work of Snyder et al. [2003] show no statistically significant relationship between width and erosion rate, many other studies do show a correlation (see results above). We note, however, that the exponents from the regressions in these studies also vary. The relationship between channel width and slope is also variable. The regressions show steep relationships for locations in the Himalaya and Taiwan, but rivers in central Italy from the data set of Wohl and David [2008] have much shallower trends (Figure 3). The data presented above introduce some important questions about the dynamics and controls of bedrock incision. Examples of these questions include: What controls the relationship between bedrock channel width and incision rate?, and Why are there variable relationships between channel width and slope? We seek to understand how channel geometry will adjust to erosion rate, sediment supply, and water discharge if we assume that both channel width and channel slope adjust to variations in these inputs.

\section{Model}

\subsection{Conceptual Overview}

[20] We hypothesize that the observed trends in the field data can be explained in terms of (1) the need for a steady state channel to equalize vertical erosion rate across the channel boundary, and (2) varying degrees of shielding of the channel bed (but not the banks) by sediment cover. To test this hypothesis, we formulate a simple model that predicts the width and slope of an idealized rectangular channel cross section. Assuming that channel slope will be minimized, a unique channel width and slope can be calculated for a given base level fall rate, sediment supply, and rock erodability for a given erosion rule [Turowski et al., 2007, 2009]. At the limit of zero sediment supply, the model reproduces the scaling relationships predicted by Finnegan et al. [2005] and modeled by Wobus et al. [2006b].

[21] Wobus et al. [2006b, 2008] present a numerical model that dynamically evolves a channel cross section with a fixed downstream water-surface slope, using the law of the wall to estimate the shear stress distribution across the channel boundary. They assumed that the boundary-normal component of erosion was proportional to the local shear stress and found that the cross section adjusted such that the vertical component of erosion velocity was uniform across the channel boundary. Using the evolution of a cross section with no sediment [see Wobus et al., 2006b, Figure 2a] as a guide, we can conceptualize and schematically represent a system that is driven toward an optimized geometry both without and with sediment cover (Figure 5). If a channel is wide for a given shear stress (compared to the optimal geometry, which is discussed below), then there will be greater shear stress on the bed than on the walls (Figure 5, cross section b). This will tend to deepen and narrow the channel such that the magnitude of stress on the walls increases until the vertical component of erosion equals the bed erosion rate (Figure 5, cross section a). On the other hand, for a channel that is relatively narrow for a given shear stress (Figure 5, cross section c), the channel widens and shallows to the point where vertical incision becomes uniform across the channel boundary (Figure 5, cross section a). We therefore anticipate a natural tendency toward a channel configuration that equalizes vertical incision rate on bed and banks, as observed in the numerical model of Wobus et al. [2006b, 2008]. We note that our assumption of a fixed channel shape (rectangular) is a limitation since in reality the entire channel boundary is free to adjust when erosional imbalances exist, such as in the case of the Wobus et al. [2006b] model; however, we feel our simplification of a fixed shape is justified since the principle that vertical erosion must be equal across the channel boundary remains true for any steady state channel shape.

[22] Now imagine adding sediment to the channel bed of cross section a in Figure 5. Sediment cover inhibits vertical erosion on the bed, but the sidewalls will continue to erode at their previous rate (Figure 5, cross section d). Because the wall erosion rate is greater than the bed erosion rate, there will be a tendency for the channel to widen (Figure 5, cross section e). Assuming that base level lowering continues unabated, the reduction in overall incision rate will also lead 


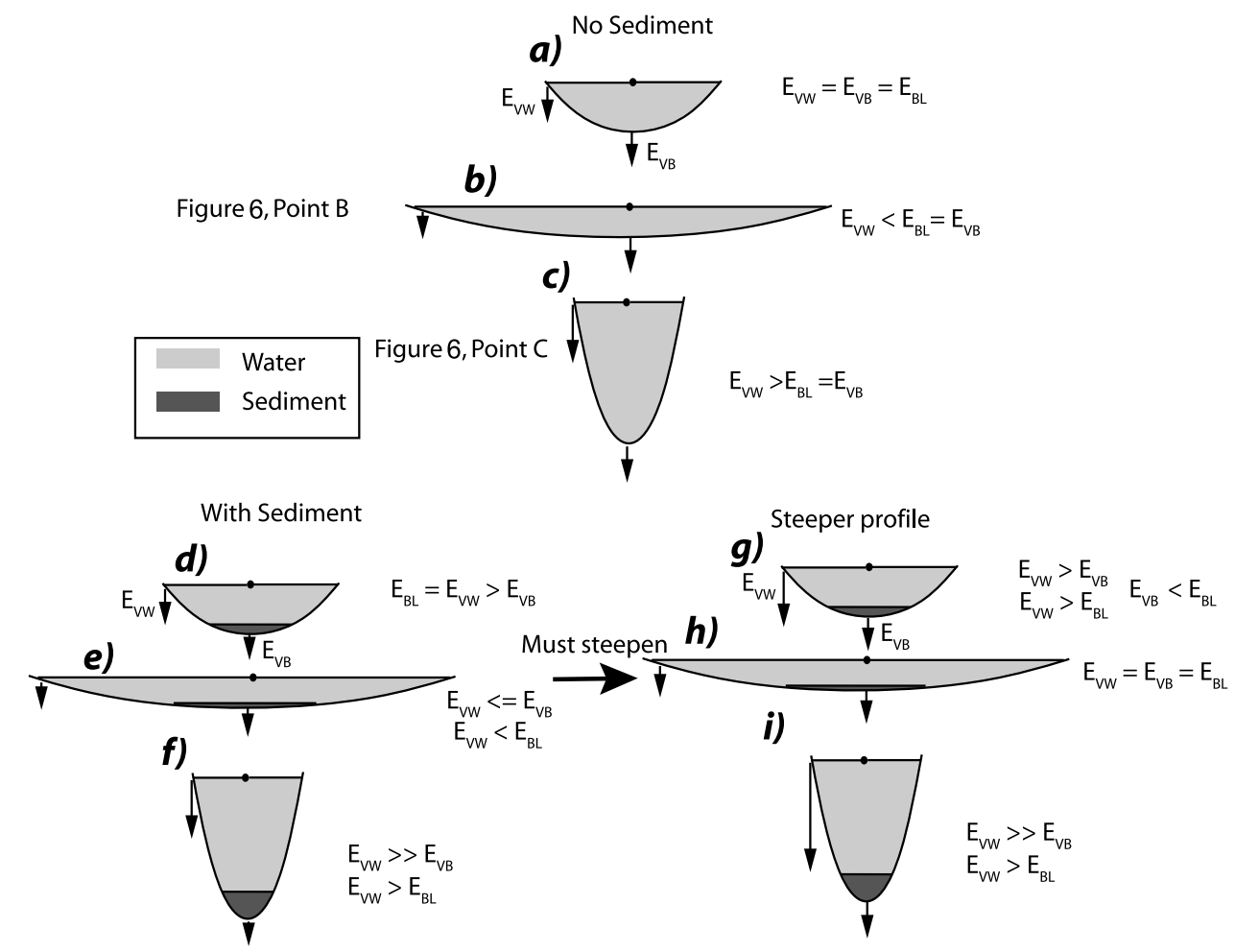

Figure 5. Conceptual model for the adjustments of channel geometry to an optimized geometry. If channel is too wide (cross section b), vertical incision in the channel center will outpace vertical incision on the walls, and the channel will narrow (vice versa if the channel is too narrow (cross section c)). When sediment is added, vertical erosion is reduced in the channel center but not the walls, so the channel will widen (from cross section $\mathrm{d}$ to e). It will also need to steepen in order to maintain the same effective shear stress to continue eroding at the base level fall (cross section h). $E_{V W}$ is the vertical rate of erosion on the channel walls. $E_{V B}$ is the vertical rate of erosion on the channel bed, and $E_{B L}$ is the rate of base level fall.

the channel to steepen, until the incision rate has increased to once again match the base level fall rate (Figure 5, cross section $\mathrm{h}$ ).

[23] To summarize, the two key elements in the conceptual model are (1) the width and slope of a bedrock channel will adjust toward an equilibrium geometry for which the vertical erosion rate along the channel perimeter matches the imposed rate of base level lowering, and (2) the presence of sediment on the bed will, all else being equal, lead to a wider, shallower, and steeper equilibrium channel.

\subsection{Optimal-Geometry Model}

[24] We follow the work of Turowski et al. [2007] in applying an optimization principle to bedrock channels. The optimized model is intended to represent the equilibrium width, depth and slope of a river channel cutting into bedrock in response to an externally imposed rate of base level fall and can be solved analytically [Turowski et al., 2007]. The model is based on the hypothesis that there will be a natural tendency for bedrock channel shapes to achieve the minimum possible slope required to generate sufficient shear stress to erode at the rate of base level fall. Although we cannot prove that a river channel will obtain such an optimal geometry, Turowski et al. [2007] showed that by making an optimization assumption, the scaling relationships between width and slope $\left(W \sim S^{-3 / 16}\right)$ proposed by Finnegan et al. [2005] as well as the relationship between width and erosion rate $(W \sim$
$E^{-0.23}$ ) found by Wobus et al. [2006b] for sediment-free channels can be reproduced. Further, the optimization model is consistent with our conceptual model described above in which the balance of vertical incision along the channel boundary is achieved at the minimum slope. The channel is fed a certain water discharge and sediment flux from its upstream contributing basin. The channel geometry is set such that (1) it erodes at the imposed rate of base level fall, and (2) it is able to transport the supplied sediment. The model predicts the relationship between channel geometry and our imposed conditions (sediment supply, base level fall rate, and water discharge). We then ask: to what extent can these predictions account for observed relationships among channel geometry and environmental conditions (water discharge, sediment supply, base level fall) in natural systems?

[25] We assume that the rate of vertical channel incision, $E$, is proportional to the average boundary shear stress [Howard and Kerby, 1983] across the channel perimeter, $\tau$, times an erodability coefficient, $k_{v}$

$$
E=k_{v} \tau
$$

Shear stress is often used as a proxy for erosion rate to capture the effects of a multitude of physical erosion mechanisms, such as bed load abrasion, plucking, and cavitation [Whipple et al., 2000]. We can invert equation (3) and calculate the required shear stress to erode at a given rate, $E / k_{v}$. The 
channel width and slope adjust such that this value is reached with the available water and sediment discharge.

[26] For simplicity, we assume a rectangular channel shape and calculate average boundary shear stress

$$
\tau=\rho g \frac{W H}{W+2 H} S
$$

\section{Effective shear stress for given sediment supply} $Q_{w}=1000 \mathrm{~m}^{3} / \mathrm{s} Q_{\mathrm{s}}=0 \mathrm{~kg} / \mathrm{s}$

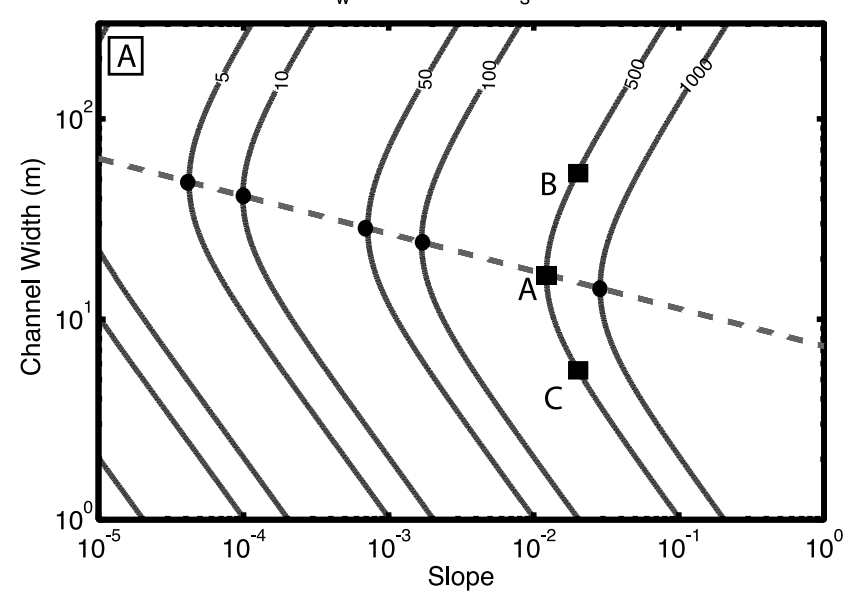

$Q_{w}=1000 \mathrm{~m}^{3} / \mathrm{s} Q_{\mathrm{s}}=5000 \mathrm{~kg} / \mathrm{s}$
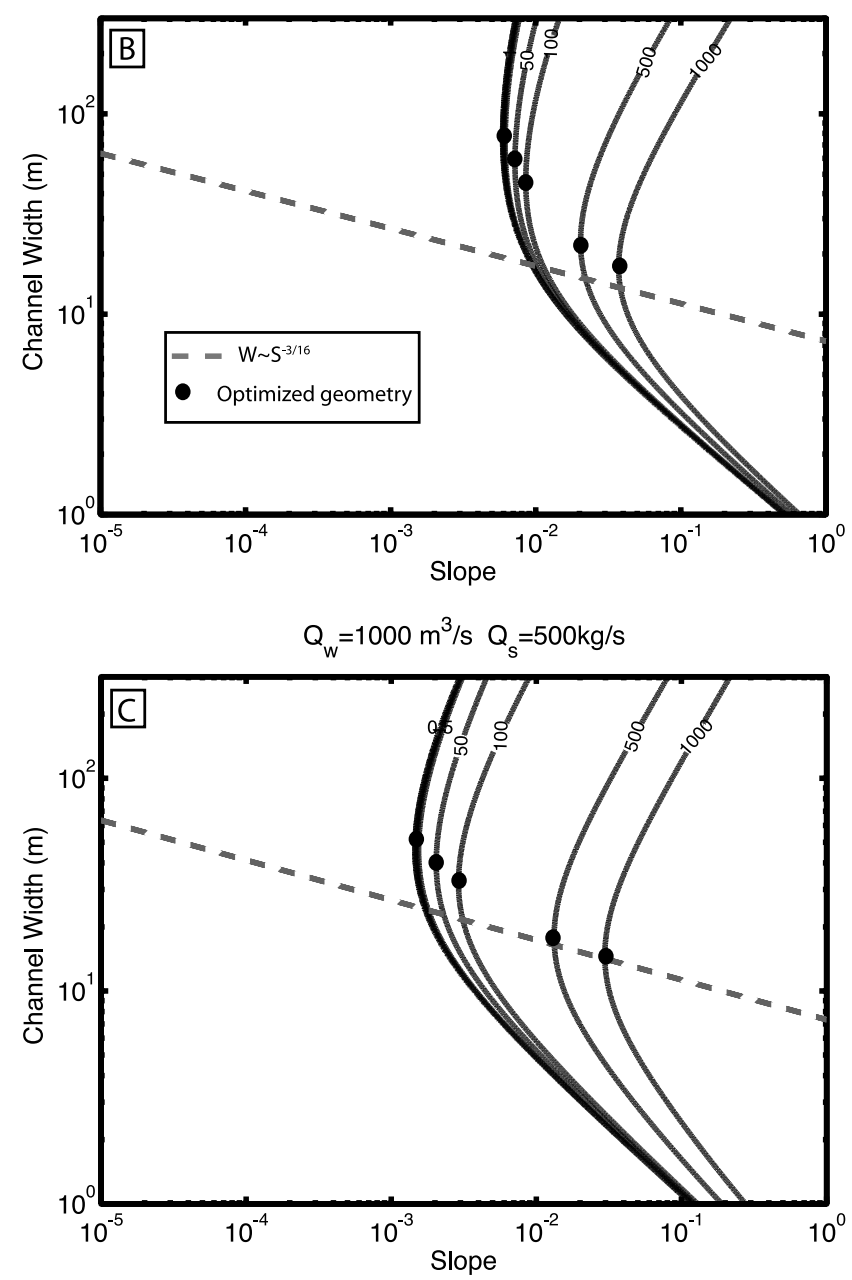

where $\rho$ is density, $g$ is gravitational acceleration, $W$ is channel width, $H$ is flow depth, and $S$ is channel slope. We calculate the flow depth iteratively by using Manning's equation for cross-section average flow velocity, $V$, and the conservation of mass $Q_{w}=V A$, where $Q_{w}$ is water discharge and $A=W H$ is the flow cross-sectional area. The velocity is calculated using Manning's equation

$$
V=\frac{1}{n}\left(\frac{A}{P_{t}}\right)^{2 / 3} S^{1 / 2}
$$

where $n$ is the Manning roughness factor, set to 0.04 (a common value for bedrock streams) in all cases in this paper, and the wetted perimeter, $P_{t}$ equals $2 H+W$. In the iterative numerical scheme, we add water depth or subtract water depth in small increments until water discharge is within $0.1 \%$ of the prescribed value [Wobus et al., 2006b; Turowski et al., 2009]. Note that we do not make the 'wide-channel' assumption (i.e., channel width is much greater than depth and thus $P_{t}=W$ and $A / P_{t}=H$ ) in calculating flow depth or shear stress; this results in a nonlinear relationship between channel geometry (width, slope, flow depth) and average boundary shear stress (Figure 6a and equation (4)).

[27] For any given discharge (and assuming no sediment supply for the time being), equations (3)-(5) allow an infinite range of slope and width combinations that would produce the necessary shear stress and erosion rate to balance the rate of base level fall (Figure 6a). For example, if the channel is relatively wide (Figure $6 \mathrm{a}$, point $\mathrm{B}$ ), friction will be dissipated over a wide perimeter, and the channel must therefore be relatively steep in order to generate sufficient shear stress. Conversely, if the channel is relatively narrow and deep (Figure 6a, point C), significant friction will be expended on the sidewalls and once again the channel must be relatively steep in order to produce sufficient stress. Between these two cases lies an equilibrium width for which the required slope is a minimum (Figure 6a, point A).

[28] We assume that the system will tend to attain the channel width at the lowest allowable slope (Figure 6a, point A) [Turowski et al., 2007]. At this point the only way to increase shear stress is to increase slope, since channel narrowing or widening will reduce average boundary shear stress. To understand the mechanism for reaching a minimal gradient, consider a channel that is wider and steeper

Figure 6. Contour plot of effective shear stress. The $y$ axis is channel width, and the $x$ axis is channel slope. All plots are for a water discharge of $1000 \mathrm{~m}^{3} / \mathrm{s}$. Dashed line is $W \sim$ $S^{-3 / 16}$ [see Finnegan et al., 2005]. Solid circles are the assumed optimized geometry for the shear stress contour of $E /\left(F k_{v}\right)$ (see text for an explanation). (a) No sediment supply case. Effective shear stress is the real shear stress. Points A, $\mathrm{B}$, and $\mathrm{C}$ represent locations where the effective shear stress equals the required shear stress; only point $\mathrm{A}$ is a stable geometry. Note the concordance with the predicted width-toslope scaling. (b) High sediment supply of $5000 \mathrm{~kg} / \mathrm{s}$. Width and slope locations diverge from $W \sim S^{-3 / 16}$. In general, channels are wider and steeper (compare to same effective shear stress values in Figure 6a). (c) Intermediate sediment supply of $500 \mathrm{~kg} / \mathrm{s}$. High effective shear stress values converge to $W \sim S^{-3 / 16}$. 
(Figure 6a, point B) than the minimum-slope point. A small perturbation that leads to channel narrowing increases shear stress on the channel bed, which in turn may promote further narrowing [Cantelli et al., 2004]. This narrower channel will incise faster due to the increase of shear stress and thus lower its slope. This scenario will continue until the channel reaches point $\mathrm{A}$, where further narrowing leads to a reduction rather than an increase in average shear stress. We point the reader to Wobus et al. [2006b, Figure 2A] for an example of a wide channel cross section adjusting to a geometry in which vertical erosion on the banks and bed are equalized. Next, consider a channel that is narrower and steeper (Figure 6a, point $C$ ) than the minimum-slope point. In such a channel, a small perturbation that leads to widening would tend to increase the average shear stress, and hence to a more rapid rate of erosion. This will lower the local slope as the river incises faster than downstream reaches. This will continue until the channel geometry equals that at point A. Channel narrowing during erosion is unlikely in this scenario since wall stresses are enhanced, keeping the channel wide as incision takes place. Additionally, the lowering of slope also increases the width of the water surface for a given discharge based on Manning's equation and mass balance. For a river at the minimized slope location, perturbations away from this configuration generate geometrical responses back toward this initial point. Everywhere else on the curve, perturbations tend to lead away from the original point.

[29] To incorporate the influence of sediment covering and protecting the underlying bedrock from erosion, we assume that the rate of vertical incision by a given shear stress is reduced by the fraction of bedrock not covered by sediment and exposed to fluvial processes.

$$
E=F k \tau_{b}
$$

We follow Sklar and Dietrich [2004] to constrain the fraction of exposed bedrock, $F$, to between 0 and 1 with the equation

$$
F=1-\frac{Q_{s}}{Q_{T}}
$$

where $Q_{S}$ is sediment supply and $Q_{T}$ is transport capacity calculated using a Meyer-Peter Mueller bed load equation [Meyer-Peter and Müller, 1948]:

$$
Q_{T}=8 \rho_{s} W\left[\frac{\tau_{b}}{\left(\rho_{s}-\rho\right) g D}-\tau_{c}^{*}\right]^{3 / 2} D^{3 / 2} \sqrt{\frac{\left(\rho_{s}-\rho\right)}{\rho} g}
$$

where $\rho_{s}$ is the density of a sediment clast, $D$ is grain size, $W$ is the width of the bed load sheet, assumed to equal channel width, and $\tau_{c}^{*}$ is the critical Shield's stress for sediment entrainment. We note other bed load transport equations have been proposed [cf. Barry et al., 2004]. To explore potential sensitivity to different models, we calculated our model results using a relationship of Wong and Parker [2006] as well as equation (8), and found no difference in the calculated trends, though the absolute values of width and slope varied by up to $50 \%$. For simplicity, we will use the original MeyerPeter and Müller [1948] formulation.

[30] Chatanantavet and Parker [2008] explored the fraction of exposed bedrock in a flume study by seeding the bed with sediment patches and holding discharge and sediment supply constant. Although some specific scenarios produced runaway bedrock exposure and burial, in general there was a linear decline in exposed bedrock with increasing the ratio $Q_{S} / Q_{T}$, thus supporting the use of such a formulation. We interpret this 'cover' term as a long-term spatial and temporal average of the magnitude of erosional inhibition by immobile bed sediment, and therefore, we use it as a proxy for longterm sediment cover. We note that other sediment cover models have been proposed [e.g., Turowski et al., 2007]; however, the difficulties in discriminating between the exponential and linear models [Turowski, 2009] lead us to choose the simpler model of Sklar and Dietrich [2004]. We can now calculate the shear stress that is required to erode at the imposed base level fall that includes the effects of sediment cover on lowering the erosional efficiency of the channel, which is equal to $E /\left(F k_{v}\right)$. Since shear stress must be positive, this places the further constraint that transport capacity is greater than sediment supply $Q_{T}>Q_{s}$. Another way to look at this is to consider the local effective shear stress, $\tau_{\text {eff }}=F \tau$, which is the temporally averaged shear stress that a point of bedrock sees as it is covered $(\tau=0)$ and uncovered ( $\tau=$ equation (4)).

[31] We set water discharge, erosion rate (e.g., rock-uplift rate or base level fall), sediment supply, erodability coefficient, and sediment grain size. Then we find the pair of width and slope values that provide the required shear stress to erode at $E$ and transport the supplied sediment, $Q_{s}$. We hypothesize that the channel configuration reached when sediment is incorporated is also optimized as was the case described for Figure 6a. This allows the calculation of channel width and slope for channels influenced by sediment cover (Figures $6 \mathrm{~b}$ and $6 \mathrm{c}$ ). We note that no channel will ever be perfectly rectangular, but this assumption allows for an efficient and tractable means of calculating open-channel flow properties. As such, the absolute values of channel geometry calculated in this exercise should be viewed with caution; however, as we will show, the resulting trends offer a robust explanation of the controls on channel geometry.

\section{Model Results and Discussion}

\subsection{Sediment-Free Channel}

[32] When sediment supply is nil, the computed scaling of channel width with erosion rate (Figure 7, solid black line) and slope (Figure 8, solid black line) for a constant discharge matches that predicted by Finnegan et al. [2005] and found numerically by Wobus et al. [2006b]. The $W / H$ ratio is also constant (Figure 9), consistent with their work. The value of our derived constant width-depth ratio for the no-sediment case is lower than that found by Wobus et al. [2006b]. We interpret this to be a result of assuming a rectangular cross section for computing flow velocity and boundary shear stress [e.g., Turowski et al., 2009]. Finally, channel width and slope are power law functions of erosion rate at all values. Channel width scales with water discharge with an exponent of 0.46 (Figure 10), within the range of field observations and similar to what Finnegan et al. [2005] proposed (exponent of 0.47$)$.

\subsection{Sediment-Mantled Channel}

[33] Adding sediment to the system changes many of the scaling relationships reported above (Figures 7 and 8 and 


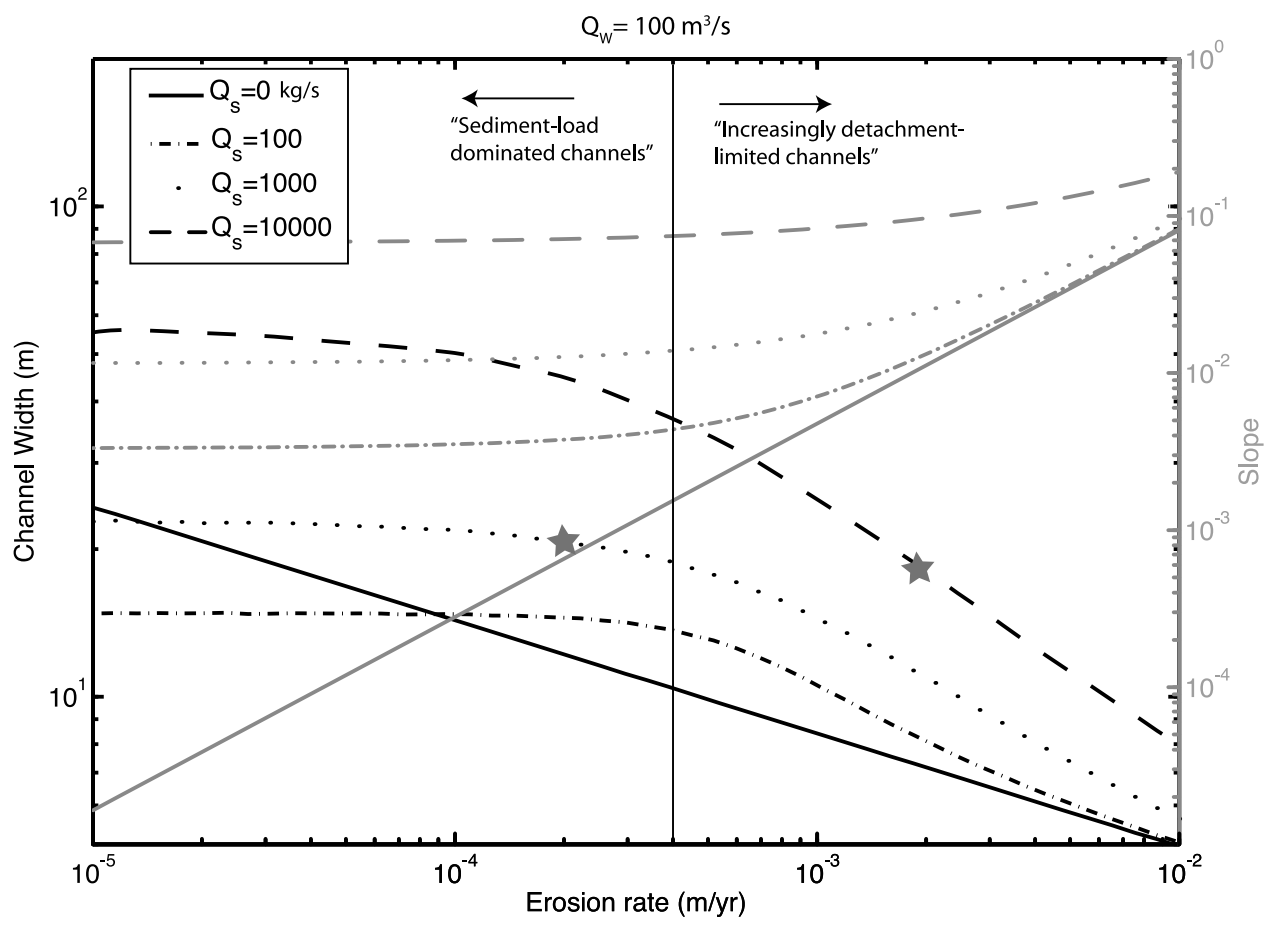

Figure 7. Model channel width and slope values versus imposed erosion rate (base level fall). Water discharge is held constant at $100 \mathrm{~m}^{3} / \mathrm{s}$. Sediment supply ranges from 0 to $10000 \mathrm{~kg} / \mathrm{s}$. Width data are in black, and slope are in gray. Note that for erosion rates less than $\sim 0.3 \mathrm{~mm} / \mathrm{yr}$ (value chosen visually from the graph), channel geometry is dominated by sediment transport requirement (except for the case of no sediment). For erosion rates greater than this value, channel width and erosion-rate relationship becomes steeper with increasing sediment supply. The gray stars represent an example of constant channel width values for a tenfold increase in erosion rate but also a tenfold increase in sediment supply. Note the slope on the solid lines (zero sediment supply) match the relationship found by Wobus et al. [2006b]. Also, the relationship between slope and erosion rate for zero sediment supply equals that predicted by a pure detachment-limited erosion model [e.g., Whipple and Tucker, 1999].

Table 2). In fact, the results suggest that a simple power law scaling between channel width and either slope or erosion rate may not explain bedrock channel geometry in all settings (Figures 7 and 8). Note that similar results using a different erosion model were found by Turowski et al. [2007, 2009]. At low incision rates, the channel width and slope are dominated by the necessity to transport the supplied sediment (Figure 7). Essentially, the critical shear stress required to entrain and transport the supplied particles of size $D_{50}$ (equation (8) and Figure 11) is much greater than the shear stress required to erode at the imposed base level fall [Johnson et al., 2009]. As erosion rate increases, slope and width only have to adjust slightly to produce the required effective shear stress, leading to an almost horizontal line for lower erosion rates (Figure 7). In the case of no sediment cover, all of the shear stress is 'used' on eroding bedrock and none is 'wasted' on transporting sediment. To erode at twice the rate such a river must double shear stress and thus significantly alter its geometry. This is not the case for rivers in which significant sediment cover persists. To double the bedrock erosion rate and continue transporting sediment at the supply rate only requires a small fractional change in the magnitude of shear stress since the shear stress required to transport sediment is much greater than the shear stress required to erode at base level fall. In other words, when significant sediment cover is introduced, a nearly constant channel geometry is achieved at lower erosion rates.

[34] As erosion rate continues to increase, there is a transition where changes in width and slope begin to increase with increasing erosion rate. This occurs around the point where the shear stress required to transport the supplied sediment is roughly the same as that necessary to erode at the base level fall in a sediment-free channel (Figure 11). This causes a strong correlation between channel width and incision rate because significant changes in shear stress are required to continue eroding at the rate of base level fall. As incision rate increases, the necessary shear stress to incise into bedrock becomes important (Figure 11). At very high erosion rates, $Q_{T} \gg Q_{s}$ and the system approaches the no-sediment end-member (i.e., $F \sim 1$ ). As the system approaches a sediment cover-free situation, almost all the potential shear stress can be applied to eroding bedrock. In these cases, the model relationships proposed by Finnegan et al. [2005] and found by Wobus et al. [2006b] are reproduced and a constant $W / H$ ratio is achieved.

[35] At low slopes, the $W / H$ ratio decreases steeply with increasing erosion rate (Figure 9). A transition occurs at intermediate slopes where the $W / H$ curve begins to level off and approaches a constant value. In our optimization model, the constant $W / H$ ratio, found when $Q_{s}=0$ or $Q_{T} \gg Q s$, is the 


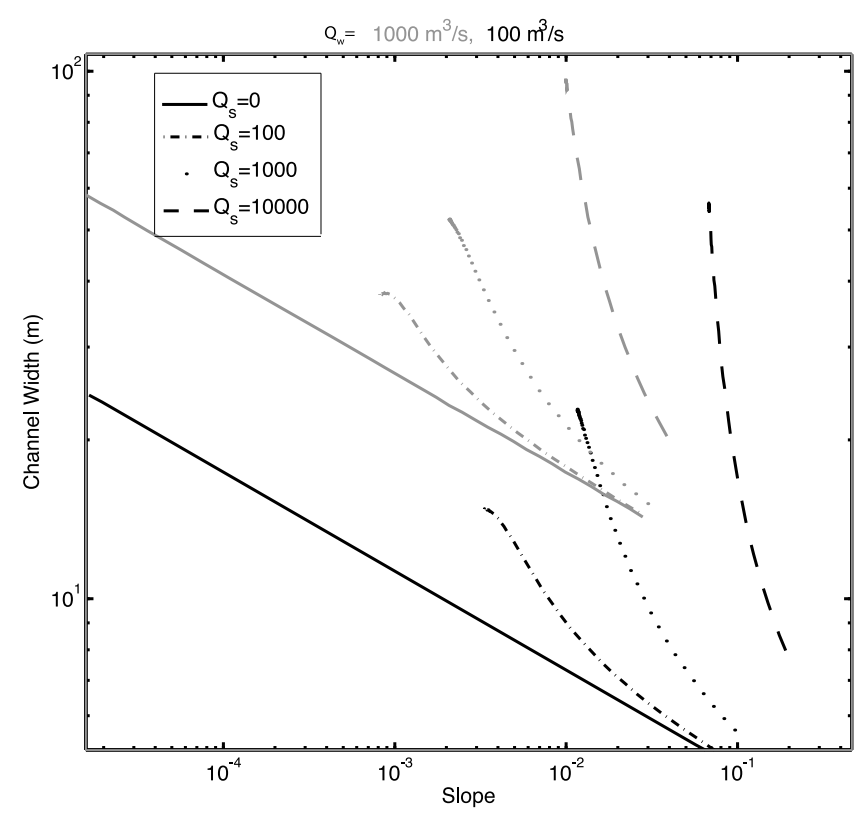

Figure 8. Model channel width versus slope for water discharge of $1000 \mathrm{~m}^{3} / \mathrm{s}$ (gray) and $100 \mathrm{~m}^{3} / \mathrm{s}$ (black). Sediment supply ranges from 0 to $10000 \mathrm{~kg} / \mathrm{s}$. In general, the higher discharge leads to wider and shallower channels. The variation in width and slope are generated by prescribing the range of erosion rates from Figure 7 . Note the slope on the solid lines (zero sediment supply) match the relationship predicted by Finnegan et al. [2005].

geometrical configuration in which channel width has a relatively weak dependence on erosion rate $\left(W \sim E^{-0.23}\right)$. For low erosion rates, only minor adjustments to the $W / H$ ratio occur for a given change in erosion rate. A transition occurs at moderate incision rates where the $W / H$ ratio becomes strongly dependent on erosion rate (i.e., a relatively small increase in erosion rate causes a significant decrease in the $W / H$ ratio). At high erosion rates, the $W / H$ ratio approaches a constant. It is clear that a constant $\mathrm{W} / \mathrm{H}$ ratio is not appropriate for channels where sediment cover is important in controlling incision rates. Using a full saltation-abrasion model, Turowski et al. [2007] came to a similar conclusion in that a constant $\mathrm{W} / \mathrm{H}$ ratio is likely not appropriate when sediment-dependent processes are important. Their model predicts an almost constant $\mathrm{W} / \mathrm{H}$ ratio at low erosion rates. As erosion increases, the optimized saltation-abrasion model predicts an increase in $W / H$ ratio, followed by a 'roll over' in the curve and finally a decrease. Field observations on the relationship between $\mathrm{W} / \mathrm{H}$ ratio and erosion rate (Figure $4 \mathrm{~b}$ ) appear to favor a more monotonic relationship, which is predicted by our simpler model, though the limited range of data ( 2 orders of magnitude) may not capture the full trend of the relationship.

[36] Differences in the modeled scaling relationships can be difficult to compare quantitatively with one another since simple power law scaling relationships break down; however, qualitative changes in the relationships are clear. Among these, the relationship between channel width and discharge becomes slightly weaker with increasing sediment concentration (Figure 10). In order to compare different model outputs and field data, we will use the term sediment concentration to mean the mass of bed load moved per unit discharge of water. It should be noted that the scaling relationship between width and water discharge in Figure 10 does not account for the likely increase in sediment supply with increasing discharge. Doing so, that is assuming sediment supply scales linearly with $Q_{w}$ or as $Q_{w}^{0.5}$ [e.g., Parker et al. [2007], actually results in a fairly consistent dependence of channel width on water discharge (Figure 12) with exponents ranging only from $\sim 0.46-0.52$.

[37] As suggested by others [Finnegan et al., 2005; Whittaker et al., 2007a; Wobus et al., 2006b; Lague, 2010], the model illustrates the point that channel width and slope are interdependent. As sediment concentration increases, a channel becomes steeper for a given erosion rate (Figure 7). Channels tend to be wider with increasing sediment concentration except for one scenario of low incision rate. Going from zero sediment concentration to a very small $Q_{s}$ actually narrows the channel (but also steepens it, keeping with an optimized geometry) because the shear stress to erode at slow rates of base level fall in a sediment free channel is lower than the critical stress to entrain the $D_{50}$. Any additional sediment then widens the channel. Alternatively, for a given sediment supply, a steeper channel is coincident with a narrower channel (Figure 8). Holding water discharge constant, an increase in sediment supply causes a steeper relationship between channel width and slope (Figure 8).

\subsection{Model Implications}

[38] The model predicts a range of observations of channel width in natural channels. Some important predictions are:

[39] 1. As sediment concentration increases, the relationship between channel width and erosion rate becomes steeper for moderate to high erosion rates.

[40] 2. As sediment concentration increases, the relationship between channel width and slope becomes steeper and diverges from a power law relationship.

[41] 3. For a given sediment supply, the shear stress required to transport the sediment dominates the channel morphology for relatively low erosion rates. As erosion rate increases, a transition occurs and the shear stress is dominated by the need to erode rock at the rate of base level fall.

[42] 4. A constant $W / H$ ratio is only appropriate for the detachment-limited (no-sediment) end-member of the fluvial system. Otherwise it is strongly related to channel slope and erosion rate.

[43] At the limit of zero sediment supply, the system produces the scaling relationships proposed by Finnegan et al. [2005] and Wobus et al. [2006b] [Turowski et al., 2007]. This special case deserves attention as it reveals a compelling insight into the optimization of channel dynamics. As shown by Wobus et al. [2006b], when the slope and water discharge are set, the channel geometry adjusts so that the vertical rate of erosion is the same across the channel cross section and a constant width to depth ratio is achieved. This constant is not a universal value. It will depend on the specific channel shape (e.g., ' $\mathrm{V}$ ' shaped or rectangular) and on the roughness of bedrock features [Turowski et al., 2009]. The model is also consistent with the flume observations of Finnegan et al. [2007] and Johnson and Whipple [2007] that a channel widens when sediment supply is increased.

[44] Although we are not explicitly accounting for wall erosion in the model, we can make some predictions based on our results and the model of Wobus et al. [2006b]. Their 

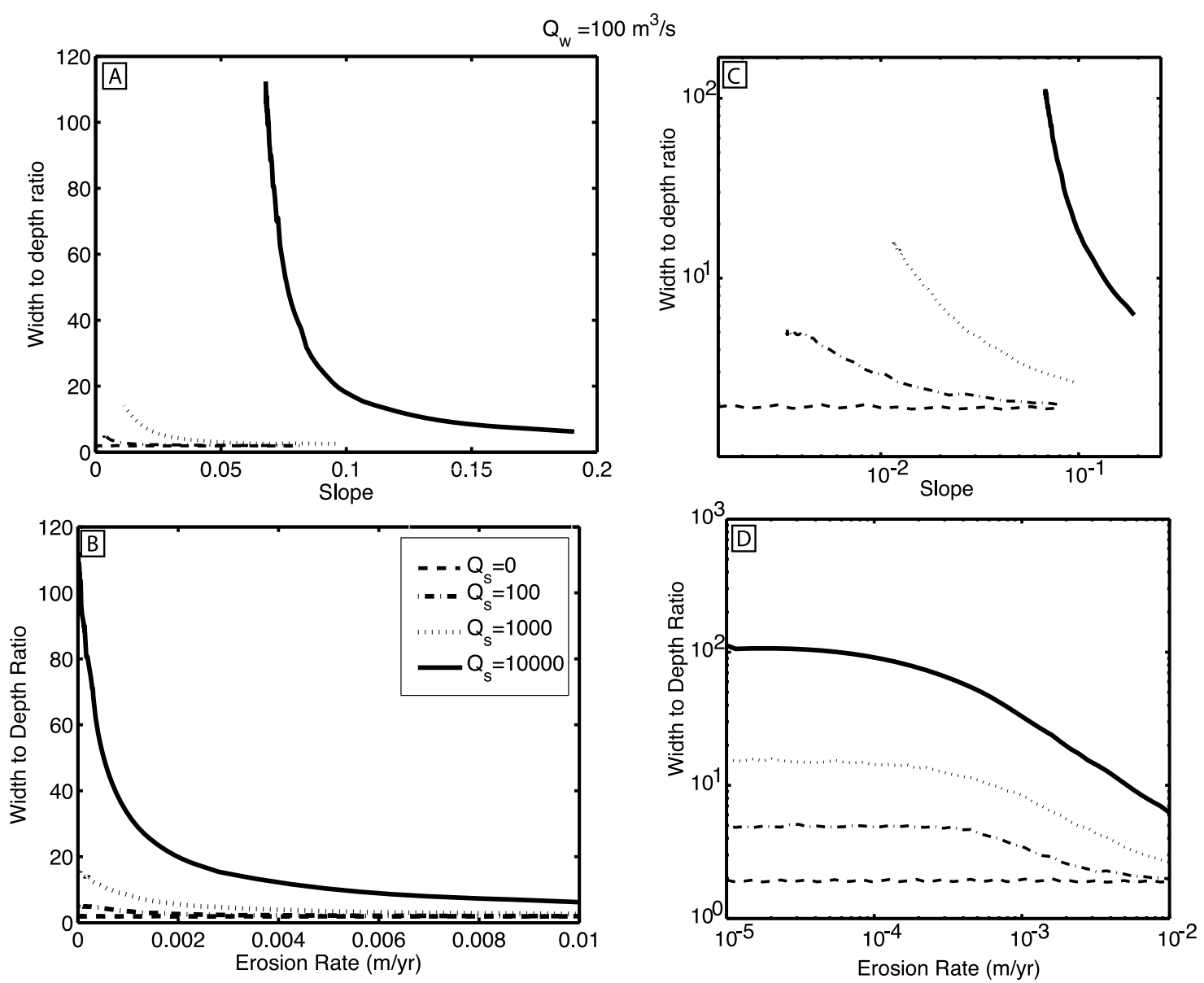

Figure 9. Model width to depth ratio $(W / H)$ versus (a) slope and (b) erosion rate. For zero sediment supply, $W / H$ ratio is constant. Relationships become more nonlinear with increasing sediment supply. (c and d) Slope and erosion rate as in Figures $9 \mathrm{a}$ and $9 \mathrm{~b}$ but in $\log -\log$ space.

model assumes that the erodability is uniform across the channel boundary, such that for any nonhorizontal surface, the required local shear stress to vertically erode at the base level fall rate will be less than the shear stress required at the channel bottom. Essentially, this can be quantified as

$$
k \frac{\tau_{L}}{\cos \left(\alpha_{\mathrm{L}}\right)}=k \tau_{b}=E_{b}
$$

where $\tau_{L}$ is the local shear stress, $\alpha_{L}$ is the local boundary angle with respect to the horizontal, and $\tau_{b}$ is the shear stress at the channel center. At equilibrium, wall stresses only differ from the bed stresses by the factor $1 / \cos \left(\alpha_{L}\right)$. As sediment is added, the channel bottom erodability is reduced but the walls remain the same. Holding base level constant, the relationship changes to

$$
k \frac{\tau_{L}}{\cos \left(\alpha_{\mathrm{L}}\right)}=F k \tau_{b}=E_{b}
$$

Wall stresses now differ from bed stresses by a factor of $1 /\left(F \cos \left(\alpha_{\mathrm{L}}\right)\right)$. Since $E_{b}$ remains the same, $\tau_{b}$ must increase when $F$ decreases. If the increase in $\tau_{b}$ also increases $\tau_{L}$, then it follows that $\tau_{L} / \cos \left(\alpha_{L}\right)$ must eventually decrease. The only way to accomplish both of these requirements is to steepen (increase $\tau_{b}$ ) and widen (lower $\alpha_{L}$ and/or $\tau_{L}$ ) the channel. Narrowing the channel would increase $\alpha_{L}$ and $\tau_{L}$.

\subsection{Comparison With Field Data}

[45] Our model can explain the range of observations of channel geometry in the field. It explains why in some cases channel width is strongly influenced by erosion rate and why in other cases the relationship is less sensitive. Further, the model predicts a $W / H$ ratio that is inversely related to erosion rate at low incision rate values and reduces to almost a constant with increasing erosion rate and/or slope, similar to what is observed (Figure 9). A similar interpretation of the data could be made using the results of Turowski et al. [2007], who used a process specific saltation-abrasion model; however, the relative importance of different processes (e.g., abrasion, plucking, etc) are likely to be variable among the various rivers we examine. Shear stress should correlate with the rate of most processes of bedrock incision [Whipple et al., 2000]. Thus we prefer to interpret the data based on our simple model of a shear stress erosion proxy, to incorporate the effects of the various processes of bedrock river incision, along with a cover model [Sklar and Dietrich, 2004] to account for the effect of static sediment protecting underlying bedrock. 

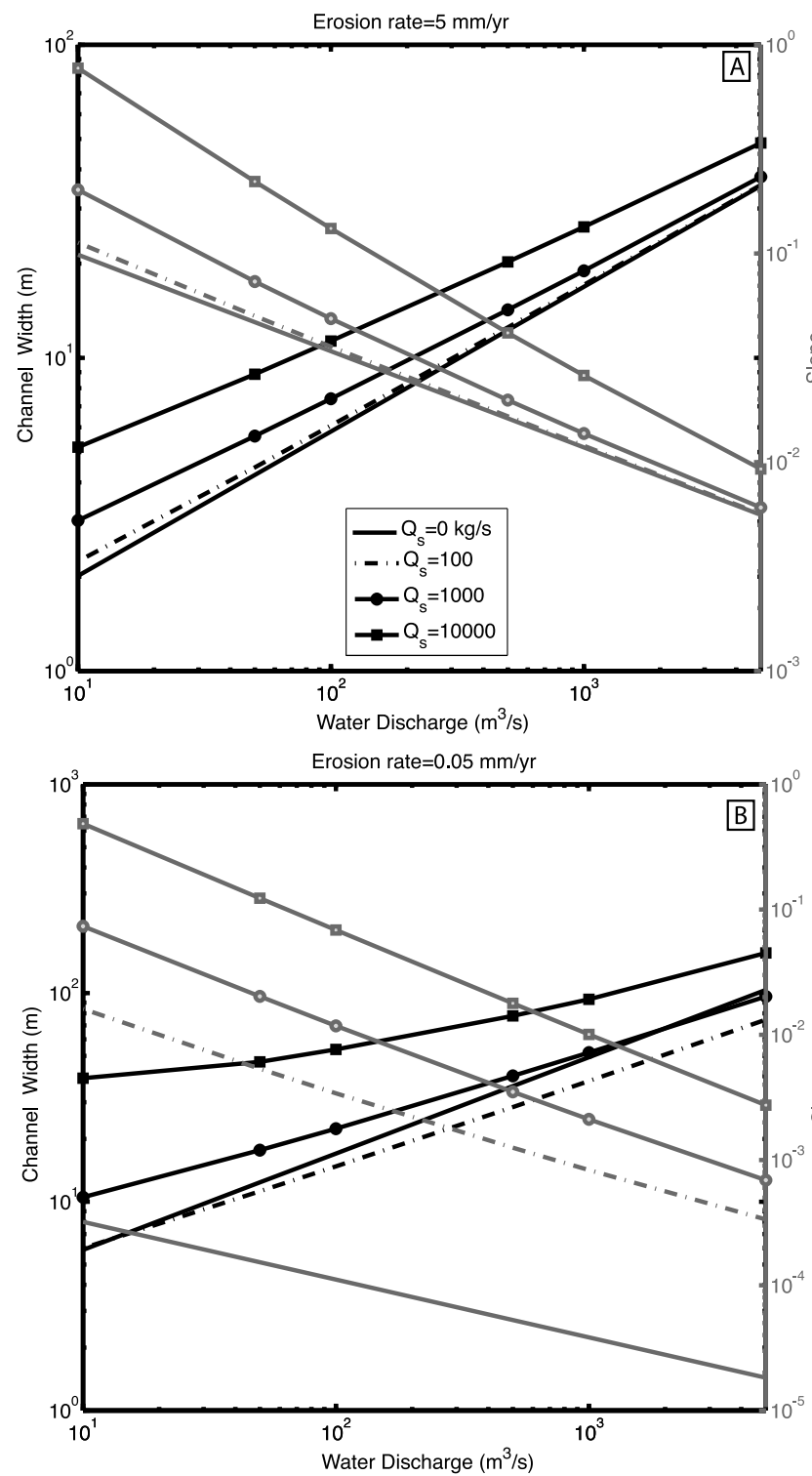

Figure 10. Channel width and slope versus water discharge for various sediment supply values. (a) Erosion rate equals $5 \mathrm{~mm} / \mathrm{yr}$; (b) erosion rate equals $0.05 \mathrm{~mm} / \mathrm{yr}$. Sediment supply was constant for increasing water discharge.

Table 2. Model-Predicted Scaling Coefficients and Exponents for Our Interpreted Detachment-Limited Parameter Space ${ }^{\mathrm{a}}$

\begin{tabular}{lcccc}
\hline & $\begin{array}{c}W \sim S \\
\text { Coefficient }\end{array}$ & Exponent & $\begin{array}{c}W \sim E \\
\text { Coefficient }^{\mathrm{b}}\end{array}$ & Exponent \\
\hline No sediment & 3.09 & -0.19 & 1.72 & -0.23 \\
$10 \mathrm{~kg} / \mathrm{s}$ & 2.54 & -0.25 & 1.42 & -0.27 \\
$100 \mathrm{~kg} / \mathrm{s}$ & 1.77 & -0.37 & 1.05 & -0.33 \\
$1000 \mathrm{~kg} / \mathrm{s}^{\mathrm{c}}$ & 0.82 & -0.73 & 0.88 & -0.40 \\
\hline
\end{tabular}

${ }^{a}$ These values are not meant to be universal. They are shown to provide an example of how sediment may change these relationships. Note that $Q=100 \mathrm{~m}^{3} / \mathrm{s}$.

${ }^{\mathrm{b}}$ Inferred detachment-limited parameter space $>0.5 \mathrm{~mm} / \mathrm{yr}$.

${ }^{\mathrm{c}}$ Note that the relationship does not follow a pure power law form.

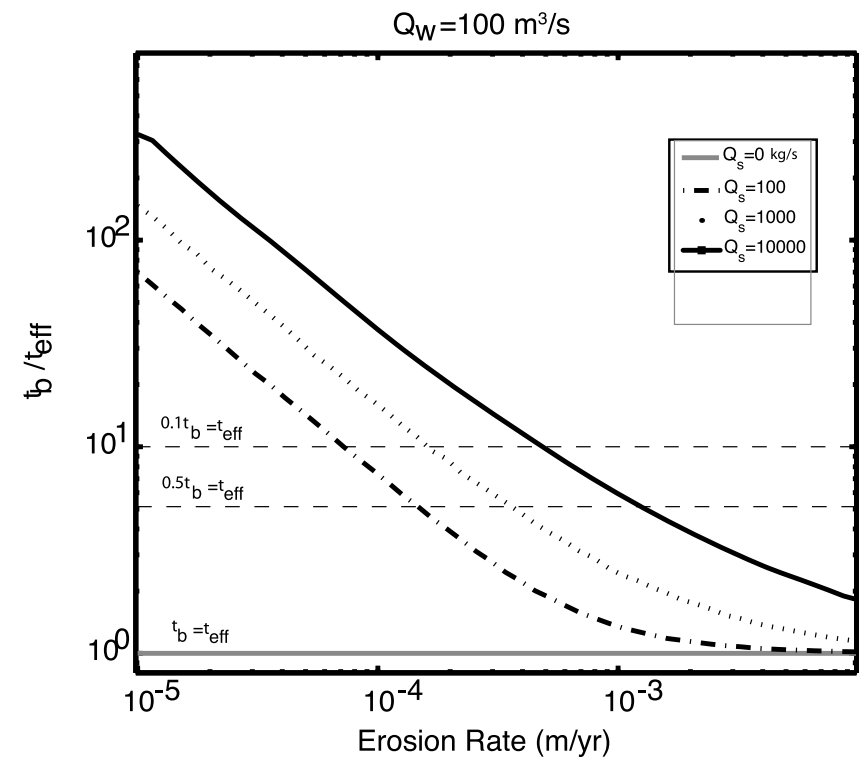

Figure 11. Ratio of real shear stress to the effective shear stress that a column of bedrock sees as it is covered and uncovered versus erosion rate. The ratio is equivalent to $1 / F$. A range of sediment supply values are shown. For $Q_{s}=0$, shears stress and effective shear stress are equal, and system is detachment limited at all erosion rates. Dashed horizontal lines denote where the effective shear stress is $10 \%$ and $50 \%$ of the real shear stress. As erosion rate increases, the system approaches the detachment limited end-member (real shear roughly equals effective shear stress). For lower sediment supply values, system goes to detachment limited end-member at lower erosion rates.

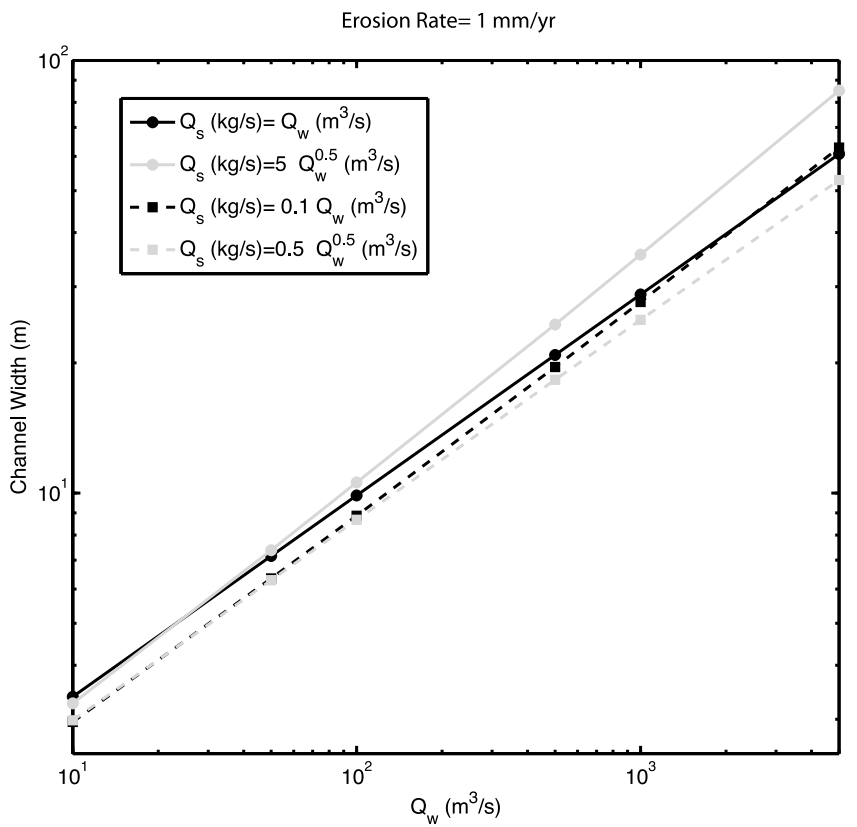

Figure 12. Channel width versus water discharge for sediment supply values that are a function of water discharge. Note the similarity in scaling for the various sediment supply functions. 
[46] In general, areas with relatively high basin-wide erosion rates, where we might expect a relatively high sediment concentration (e.g., Taiwan and the Himalayas), show a strong correlation between channel width and erosion rate/ slope, for example for the Peikang River in Taiwan, the scaling is $W \sim E^{-0.4}, W \sim S^{-0.6}$, although the relationship with slope is not necessarily linear in log-log space. Conversely, regions in which we expect a lower sediment concentration due to lower regional erosion rates [Whittaker et al., 2007b; Wohl and David, 2008] show weaker relationships between width and erosion rate $\left(W \sim E^{-0.1}-E^{-0.2}\right)$ and slope $(W \sim$ $S^{-0.2}$. We now analyze each data set individually, considering the implications of the channel geometry model. We note that because of the comparison between different basins, the data of Duvall et al. [2004] and Snyder et al. [2003] only allow comparisons of two points for each data set and thus 'scaling' relationships reported for these basins should be considered with extreme caution. We will attempt to compare different areas in terms of relative sediment flux (with respect to $Q_{w}$ ); however, we note that bed load sediment flux is rarely reported.

\subsubsection{Santa Ynez Mountains}

[47] Differential incision in the Santa Ynez Mountains $(0.75$ to $5 \mathrm{~mm} / \mathrm{yr})$ yields a threefold narrowing of channels in the high incision zone, as compared with only a twofold increase in slope for a given discharge [Duvall et al., 2004]. The model of Finnegan et al. [2005] would suggest only a $\sim 14 \%$ decrease ( $\sim 1.2$-fold narrowing) in channel width with a twofold increase in slope. However, if sediment concentration is high, as suggested by the high rates of catchment erosion for even the 'low incision zone' [Willis and Griggs, 2003], we would expect the relationship between channel width and slope to be much stronger (Figure 8). In other words, the steep relationship between width and either erosion rate or slope, relative to the theoretical prediction for a purely detachment-limited channel, suggests that the shear stress required to transport the sediment load in these rivers is comparable to or greater than the shear stress required to erode at the base level fall rate.

\subsubsection{Peikang River, Central Taiwan}

[48] Taiwan has a very high sediment flux even compared to its relatively high water discharge [Dadson et al., 2003; Fuller et al., 2003]. In the context of our optimized channel geometry model, this implies 3 predictions. First, channel width will have a strong (steep) inverse relationship with incision rate for moderate to high rates of incision. Second, channel $W / H$ ratio will vary inversely with both slope and erosion rate until a constant is reached. Third, channel slope will not correlate strongly with erosion rate until a constant $W / H$ is approached. All of these predictions are met by the Peikang River in central Taiwan (Figures 2 and 3) [cf. Yanites et al., 2010]. Yanites et al. [2010] show a strong correlation between shear stress and incision rate but only when variation in channel width is included. Slope variations along much of the studied reach are minimal (slopes corrected for drainage area vary by less than a factor of 2), despite a threefold to tenfold variation in Holocene incision rates (from $\sim 1-2 \mathrm{~mm} / \mathrm{yr}$ up to $6-10 \mathrm{~mm} / \mathrm{yr}$ ). However, upstream of where direct constraints on river incision are present, there is an anomalously steep reach (5 to 6 times steeper for a given drainage area than the downstream reach) where the $W / H$ ratios become constant. Based on the structural architecture, hillslope morphology, and estimated shear stress along the river [Yanites et al., 2010], we infer that this reach is eroding much faster $(\sim 15 \mathrm{~mm} / \mathrm{yr})$ than the downstream reaches, suggesting that the geometry is being set by the need to erode at the imposed base level. By contrast, the geometry in the downstream reach is set by both the sediment supplied from upstream and the local base level fall. This suggests that in central Taiwan, very rapid incision (or rock uplift) is necessary to push the river system near the detachment-limited end-member.

\subsubsection{Central Nepal}

[49] Lavé and Avouac [2001] found a strong correlation between channel width and incision rate for both the Bakeya and Bagmati rivers, but only the Bakeya has measurably steeper slopes where it is eroding faster. In light of our model, this may suggest that the Bagmati has a much higher relative sediment concentration than the Bakeya. Such an inference is consistent with the regional geology. The Bagmati flows through a reach of unconsolidated conglomerates just upstream, and therefore it enters the bedrock reach with a fullcapacity load of sediment. The model implies that such a sediment-rich river should adjust its shear stress almost entirely through changes in channel width, as is observed. By contrast, the Bakeya River modulates its shear stress with both channel narrowing and steepening. Even though we expect that the Bagmati has a higher sediment concentration, it is clear that both rivers have significant sediment loads for their water discharge. This is apparent in the steep scaling exponents between width and erosion rate for the Bagmati $(\sim-0.67)$ and Bakeya $(\sim-0.62)$. The lack of correlation between width and slope along the Bagmati is interesting; however, the assumption of constant discharge along this river may be questionable, as the presence of a large tributary junction in the study reach may confound the relationship. There might very well be a correlation, but given the DEM resolution and other inherent noise in a natural system, it may be too small to detect. For example, Figure 7 shows that for high relative sediment supply, increasing erosion rate from $0.1 \mathrm{~mm} / \mathrm{yr}$ to $1.0 \mathrm{~mm} / \mathrm{yr}$ causes a significant change in channel width, but little detectable change in slope. Although the exact erosion rate values do not match the Bagmati, the concept is still the same: when there is a high sediment supply, increases in erosion rate may be more apparent in changes in channel width rather than channel slope.

\subsubsection{Central Italy}

[50] Whittaker et al. [2007a, 2007b] show that the purely detachment-limited end-member presented by Finnegan et al. [2005] underestimates measured channel width in steep, tectonically active catchments in Italy. A nonconstant $W / H$ ratio further supports this assumption; however, the upper values of the $W / H$ ratio are still relatively low compared to the data from Taiwan. We interpret this to mean that the Italian rivers are closer to the detachment-limited endmember than the more sediment-laden study reaches along the Peikang River in Taiwan, but they are not completely detachment-limited [Cowie et al., 2008]. This would explain why the relationship between reference channel width and erosion rate is less steep than for the channels in Taiwan and Nepal.

\subsubsection{Global Data Set}

[51] Data from Wohl and David [2008] come from bedrock rivers all around the world with different climates and 
lithologies (e.g., Colorado, New Mexico, Panama, Japan, India, and Eastern U.S.). In spite of this, their data exhibit broad correlations between channel width, slope, and erosion rate estimated wherever such data exist. We include their data because the consistency of estimating water discharge allows the comparison between these rivers in different regions. Most locations are eroding relatively slowly (all but one location at $<1 \mathrm{~mm} / \mathrm{yr}$ ). The scaling relationships suggest that these reaches belong to the theoretical bedrock erosion regime in which the detachment of intact bedrock is the limiting factor for the rate of incision. We suggest that this is the case because of relatively low bed load sediment concentration. For lower regional erosion rates, less sediment is required to be carried by the stream. Therefore, the detachment limited end-member is achieved at relatively modest base level fall rates because transporting the bed load is relatively easy.

\subsubsection{Mendocino Triple Junction}

[52] The model can also explain situations in which there appears to be no connection between channel width and incision rate. Snyder et al. [2003] found no statistically significant difference in channel widths for a given discharge between basins in a high uplift zone $(\sim 4 \mathrm{~mm} / \mathrm{yr})$ and low uplift zone ( $\sim 0.5 \mathrm{~mm} / \mathrm{yr})$. In fact, channels may actually be slightly wider in the high uplift zones even though the opposite would be expected if sediment concentration were the same. One might expect greater sediment concentration in the high uplift zone, which would cause wider channels and thus channel width can be seemingly disconnected from incision rate. If this is indeed the case (i.e., the narrowing due to higher erosion rate is balanced by the increase in sediment concentration (see the gray stars in Figure 7), then the model would also predict steeper slopes. The high uplift zone is indeed steeper by about a factor of two.

\subsubsection{Other Data Sets}

[53] The data from the Tsangpo River in the eastern Himalaya show a steep inverse relationship between channel width and slope. The scaling exponent of -0.34 (Table 1 ) is steeper than the predicted value of -0.1875 (or $-3 / 16$ ) for a purely detachment-limited case [Wobus et al., 2006b; Finnegan et al., 2005; this study]. The relationship, however, is consistent with our model for a river carrying significant sediment load and the interpretation of Finnegan et al. [2008] who suggested that sediment cover was an important factor controlling bedrock incision in their study area.

[54] A known gradient in rock-uplift and erosion rates exists in the San Gabriel Mountains of southern California [Blythe et al., 2000]. Whipple [2004] reports no discernable difference in normalized channel width along this gradient. The model allows for such an observation since both erosion rate and sediment supply influence channel width (for a given discharge), so regions exhibiting variable erosion rates may not show differences in channel width if the relative sediment supply is greater in the higher-erosion-rate zones.

\subsection{Model Limitations and Future Direction}

[55] It is clear that slope and width are fundamental controls on bedrock incision processes. Studies in places like the Himalaya and Taiwan, where sediment concentration is expected to be high, must account for variation in channel width to properly estimate erosion potential. Further, our results, and those of Stark [2006], Wobus et al. [2006b], and
Turowski et al. [2007] suggest that channel slope cannot adjust without changing the width and vice versa. Thus models that only allow slope to control the erosive potential of a river may be missing a fundamental morphological control on the dynamics and transient responses of river response to tectonic and climatic variables.

[56] The primary concern for this study was to consider the influence of base level, sediment supply, and water discharge on channel geometry. We have ignored the influence of changing grain size or different lithologies in understanding controls and limits on bedrock river geometries. This offers a potentially rich path of future research. We acknowledge that this channel geometry framework will not explain channel geometry at every bedrock river reach, but we are encouraged by the ability to explain a range of seemingly contradictory field data relationships. This is merely meant to serve as a framework for considering relationships for a system at equilibrium with the local environmental variables. There are many reasons to question whether a river is in equilibrium with respect to base level fall, water discharge, and sediment supply. For example, stochasticity of climate, tectonic, and hillslope events will cause drifting from an equilibrium channel geometry. Although a full analysis of the dynamics of a channel to such a perturbation is beyond the scope of this simple model, the documented response of Gower Gulch (drainage area $5.8 \mathrm{~km}^{2}$ ) in Death Valley is an example of a system adjusting to a new channel geometry [Snyder and Kammer, 2008]. In this case, an anthropogenic channel diversion of Furnace Creek Wash (drainage area $439 \mathrm{~km}^{2}$ ) in 1941 has caused significant channel geometry changes in the decades that followed. We note that the channel geometry adjustments (e.g., narrowing in knickzones and widening in response to the increase water and sediment flux elsewhere) and the correlation between width and slope observed in that study are consistent with the predictions of our simple model. We hope that this framework will serve as a guide to quantify final steady state channel geometry given the environmental and state variables. The timescales and mechanisms of how the system gets to such equilibrium constitute important future issues to address.

[57] This study makes it clear that to advance the understanding of the dynamics and evolution of river systems, it is necessary to consider the evolution of the channel boundary in addition to channel slope. We suggest, as have others before us [Finnegan et al., 2005; Stark, 2006; Wobus et al., 2006b; Turowski et al., 2007], that both width and slope adjust in concert to external boundary conditions such as water discharge, base level fall, sediment supply, and lithology. Because of the interdependence between channel width and slope, it is difficult, if not impossible, to model bedrock river dynamics with a 1-D model. For example, consider the saltation-abrasion model of Sklar and Dietrich [2004] that has a strong and nonlinear dependence on sediment supply since sediment acts as both tools to abrade the rock and also cover that protects the rock from abrasion. The model, however, requires channel width to be prescribed. What happens to the width of a channel when sediment supply is changed? One might expect the rate of widening to increase with an increase in sediment supply since there are more tools to abrade the walls, but now with a wider channel, the shear stress and transport capacity have changed, possibly changing the erosive potential along the channel bed and 
boundary. Further, an increase in sediment supply can either enhance or reduce the rate of erosion on the bed, depending on, among other things, the value of channel width. This makes the posed question difficult to answer. It is clear that full mechanistic channel boundary models are what the field of geomorphology ultimately requires to understand the dynamic evolution of bedrock rivers.

\section{Conclusions}

[58] Bedrock channels tend to adjust their width and slope for a given water discharge in order to transport the supplied sediment and erode bedrock at the rate of downstream base level fall. Our model explains the range and seemingly contradictory controls on channel width in natural settings. The steepest correlation between channel width and erosion rate will occur for moderate to high erosion rates in regions with relatively high sediment flux such as the Himalaya and Taiwan, where a significant shear stress is required to transport the bed load. When the transport capacity is much greater than the sediment supply, channel width has the weakest dependence on erosion rate and the relationships found by Finnegan et al. [2005] and Wobus et al. [2006b] are appropriate. In general, adding sediment to the system tends to widen and steepen the channel. For low incision rates, stream morphology is dominated by the need to transport supplied sediment. Channel width and slope are not independent of one another, and variations of both must be considered when deciphering the erosion potential of a river.

[59] Acknowledgments. Funding was provided by NSF grant EAR0510971 to G.T. and a NDSEG fellowship to B.Y. The manuscript benefited from thorough and constructive reviews by John Jansen and Noah Snyder. We thank Jerome Lavé and Alex Whittaker for kindly sharing their channel geometry data.

\section{References}

Amos, C. B., and D. W. Burbank (2007), Channel width response to differential uplift, J. Geophys. Res., 112, F02010, doi:10.1029/2006JF000672.

Attal, M., G. E. Tucker, A. C. Whittaker, P. A. Cowie, and G. P. Roberts (2008), Modeling fluvial incision and transient landscape evolution: Influence of dynamic channel adjustment, J. Geophys. Res., 113, F03013, doi:10.1029/2007JF000893.

Barry, J. J., J. M. Buffington, and J. G. King (2004), A general power equation for predicting bed load transport rates in gravel bed rivers, Water Resour. Res., 40, W10401, doi:10.1029/2004WR003190.

Bierman, P. R., M. Pavich, A. Gellis, and M. Caffee (2001), Erosion of the Rio Puerco Basin, New Mexico-First cosmogenic analysis of sediments from the network of a drainage large basin, Geol. Soc. Am. Abstr. Programs, 32, 314.

Blythe, A. E., D. W. Burbank, K. A. Farley, and E. J. Fielding (2000), Structural and topographic evolution of the central Transverse Ranges, California, from apatite fission-track, (U-Th)/He and digital elevation model analyses, Basin Res., 12(2), 97-114, doi:10.1046/j.13652117.2000.00116.x.

Cantelli, A., C. Paola, and G. Parker (2004), Experiments on upstream: Migrating erosional narrowing and widening of an incisional channel caused by dam removal, Water Resour. Res., 40, W03304, doi:10.1029/2003WR002940.

Chang, H. H. (1979), Minimum stream power and river channel patterns, J. Hydrol., 41, 303-327, doi:10.1016/0022-1694(79)90068-4.

Chatanantavet, P., and G. Parker (2008), Experimental study of bedrock channel alluviation under varied sediment supply and hydraulic conditions, Water Resour. Res., 44, W12446, doi:10.1029/2007WR006581.

Cowie, P. A., et al. (2008), New constraints on sediment-flux-dependent river incision: Implications for extracting tectonic signals from river profiles, Geology, 36, 535-538, doi:10.1130/G24681A.1.
Dadson, S. J., et al. (2003), Links between erosion, runoff variability and seismicity in the Taiwan orogen, Nature, 426(6967), 648-651, doi:10.1038/nature02150.

DeLong, S. B., J. D. Pelletier, and L. Arnold (2007), Bedrock landscape development modeling: Calibration using field study, geochronology, and digital elevation model analysis, Geol. Soc. Am. Bull., 119(1), 157-173, doi:10.1130/B25866.1.

Dethier, D. P., and E. D. Lazarus (2006), Geomorphic inferences from regolith thickness, chemical denudation and CRN erosion rates near the glacial limit, Boulder Creek catchment and vicinity, Colorado, Geomorphology, 75(3-4), 384-399, doi:10.1016/j.geomorph.2005.07.029.

Duvall, A., E. Kirby, and D. Burbank (2004), Tectonic and lithologic controls on bedrock channel profiles and processes in coastal California, J. Geophys. Res., 109, F03002, doi:10.1029/2003JF000086.

Finnegan, N. J., G. Roe, D. R. Montgomery, and B. Hallet (2005), Controls on the channel width of rivers: Implications for modeling fluvial incision of bedrock, Geology, 33(3), 229-232, doi:10.1130/G21171.1.

Finnegan, N. J., L. S. Sklar, and T. K. Fuller (2007), Interplay of sediment supply, river incision, and channel morphology revealed by the transient evolution of an experimental bedrock channel, J. Geophys. Res., 112, F03S11, doi:10.1029/2006JF000569.

Finnegan, N. J., B. Hallet, D. R. Montgomery, P. K. Zeitler, J. O. Stone, A. M. Anders, and L. Yuping (2008), Coupling of rock uplift and river incision in the Namche Barwa-Gyala Peri massif, Tibet, Geol. Soc. Am. Bull., 120(1), 142-155, doi:10.1130/B26224.1.

Fuller, C. W., S. D. Willett, N. Hovius, and R. Slingerland (2003), Erosion rates for Taiwan mountain basins: New determinations from suspended sediment records and a stochastic model of their temporal variation, J. Geol., 111(1), 71-87, doi:10.1086/344665.

Granger, D. E., J. W. Kirchner, and R. C. Finkel (1997), Quaternary downcutting rate of the New River, Virginia, measured from differential decay of cosmogenic ${ }^{26} \mathrm{Al}$ and ${ }^{10} \mathrm{Be}$ in cave-deposited alluvium, Geology, 25(2), 107-110, doi:10.1130/0091-7613(1997)025<0107:QDROTN> 2.3.CO;2.

Howard, A. D., and G. Kerby (1983), Channel changes in badlands, Geol. Soc. Am. Bull., 94(6), 739-752, doi:10.1130/0016-7606(1983) $94<739: \mathrm{CCIB}>2.0 . \mathrm{CO} ; 2$.

Johnson, J. P., and K. X. Whipple (2007), Feedbacks between erosion and sediment transport in experimental bedrock channels, Earth Surf. Processes Landforms, 32(7), 1048-1062, doi:10.1002/esp.1471.

Johnson, J. P. L., K. X. Whipple, L. S. Sklar, and T. C. Hanks (2009), Transport slopes, sediment cover, and bedrock channel incision in the Henry Mountains, Utah, J. Geophys. Res., 114, F02014, doi:10.1029/ 2007JF000862.

Kirkby, M. J. (1977), Maximum sediment efficiency as a criterion for alluvial channels, in River Channel Changes, edited by K. J. Gregory, pp. 429-442, Wiley, Chichester, U. K.

Lague, D. (2010), Reduction of long-term bedrock incision efficiency by short-term alluvial cover intermittency, J. Geophys. Res., 115, F02011, doi:10.1029/2008JF001210

Lavé, J., and J. P. Avouac (2000), Active folding of fluvial terraces across the Siwaliks Hills, Himalayas of central Nepal, J. Geophys. Res., 105(B3), 5735-5770, doi:10.1029/1999JB900292.

Lavé, J., and J. P. Avouac (2001), Fluvial incision and tectonic uplift across the Himalayas of central Nepal, J. Geophys. Res., 106(B11), 26,56126,591, doi:10.1029/2001JB000359.

Leopold, L. B., and T. Maddock (1953), The hydraulic geometry of stream channels and some physiographic implications, U.S. Geol. Surv. Prof. Pap., 252, 56 pp.

Meyer-Peter, E., and R. Müller (1948), Formulas for bed-load transport, in Proceedings of the 2nd Meeting of the International Association for Hydraulic Structures Research, pp. 39-64, Int. Assoc. for Hydraul. Res., Delft, Netherlands.

Montgomery, D. R., and K. B. Gran (2001), Downstream variations in the width of bedrock channels, Water Resour. Res., 37(6), 1841-1846, doi:10.1029/2000WR900393.

Nanson, G. C., and H. Q. Huang (2008), Least action principle, equilibrium states, iterative adjustment and the stability of alluvial channels, Earth Surf. Processes Landforms, 33(6), 923-942, doi:10.1002/esp.1584.

Nichols, K. K., P. R. Bierman, R. Finkel, and J. Larsen (2003), Long-term erosion and sedimentation rates of the upper Rió Chagres Basin evidence from cosmogenic ${ }^{10} \mathrm{Be}$, in International Scientific Symposium, The Rio Chagres, Panama: A Multidisciplinary Profile of a Tropical Watershed, Water Sci. Technol. Libr., vol. 52, part 3, edited by R. S. Harmon, pp. 297-313, doi:10.1007/1-4020-3297-8_20, Springer, Dordrecht, Netherlands

Parker, G., P. R. Wilcock, C. Paola, W. E. Dietrich, and J. Pitlick (2007), Physical basis for quasi-universal relations describing bankfull hydraulic 
geometry of single-thread gravel bed rivers, J. Geophys. Res., 112, F04005, doi:10.1029/2006JF000549.

Reusser, L. J., P. R. Bierman, M. J. Pavich, E. A. Zen, J. Larsen, and R. Finkel (2004), Rapid late Pleistocene incision of Atlantic passivemargin river gorges, Science, 305(5683), 499-502, doi:10.1126/ science. 1097780.

Roe, G. H., D. R. Montgomery, and B. Hallet (2002), Effects of orographic precipitation variations on the concavity of steady-state river profiles, Geology, 30(2), 143-146, doi:10.1130/0091-7613(2002)030<0143: $\mathrm{EOOPVO}>2.0 . \mathrm{CO} ; 2$

Roe, G. H., K. X. Whipple, and J. K. Fletcher (2008), Feedbacks among climate, erosion, and tectonics in a critical wedge orogen, Am. J. Sci., 308(7), 815-842, doi:10.2475/07.2008.01.

Schildgen, T., D. P. Dethier, P. Bierman, and M. Caffee (2002), ${ }^{26} \mathrm{Al}$ and ${ }^{10} \mathrm{Be}$ dating of late Pleistocene and Holocene fill terraces: A record of fluvial deposition and incision, Colorado Front Range, Earth Surf. Processes Landforms, 27(7), 773-787, doi:10.1002/esp.352.

Sklar, L. S., and W. E. Dietrich (2004), A mechanistic model for river incision into bedrock by saltating bed load, Water Resour. Res., 40, W06301, doi:10.1029/2003WR002496.

Snyder, N. P., and L. L. Kammer (2008), Dynamic adjustments in channel width in response to a forced diversion: Gower Gulch, Death Valley National Park, Calif. Geol., 36(2), 187-190.

Snyder, N. P., K. X. Whipple, G. E. Tucker, and D. J. Merritts (2003), Channel response to tectonic forcing: Field analysis of stream morphology and hydrology in the Mendocino triple junction region, northern California, Geomorphology, 53(1-2), 97-127, doi:10.1016/S0169-555X (02)00349-5.

Springer, G. S., J. S. Kite, and V. A. Schmidt (1997), Cave sedimentation, genesis, and erosional history in the Cheat River Canyon, West Virginia, Geol. Soc. Am. Bull., 109(5), 524-532, doi:10.1130/0016-7606(1997) $109<0524:$ CSGAEH $>2.3 . \mathrm{CO} ; 2$.

Stark, C. P. (2006), A self-regulating model of bedrock river channel geometry, Geophys. Res. Lett., 33, L04402, doi:10.1029/2005GL023193.

Tomkin, J. H., M. T. Brandon, F. J. Pazzaglia, J. R. Barbour, and S. D. Willett (2003), Quantitative testing of bedrock incision models for the Clearwater River, NW Washington state, J. Geophys. Res., 108(B6), 2308, doi:10.1029/2001JB000862.

Tucker, G. E. (2004), Drainage basin sensitivity to tectonic and climatic forcing: Implications of a stochastic model for the role of entrainment and erosion thresholds, Earth Surf. Processes Landforms, 29(2), 185205, doi:10.1002/esp.1020.

Turowski, J. M. (2009), Stochastic modeling of the cover effect and bedrock erosion, Water Resour. Res., 45, W03422, doi:10.1029/2008WR007262.

Turowski, J. M., D. Lague, A. Crave, and N. Hovius (2006), Experimenta channel response to tectonic uplift, J. Geophys. Res., 111, F03008, doi:10.1029/2005JF000306.

Turowski, J. M., D. Lague, and N. Hovius (2007), Cover effect in bedrock abrasion: A new derivation and its implications for the modeling of bedrock channel morphology, J. Geophys. Res., 112, F04006, doi:10.1029/ 2006JF000697.

Turowski, J. M., N. Hovius, A. Wilson, and M. J. Horng (2008), Hydraulic geometry, river sediment and the definition of bedrock channels, Geomorphology, 99(1-4), 26-38, doi:10.1016/j.geomorph.2007.10.001.

Turowski, J. M., D. Lague, and N. Hovius (2009), Response of bedrock channel width to tectonic forcing: Insights from a numerical model, theoretical considerations, and comparison with field data, J. Geophys. Res., 114, F03016, doi:10.1029/2008JF001133.

Ward, D. J., J. A. Spotila, G. S. Hancock, and J. M. Galbraith (2005), New constraints on the late Cenozoic incision history of the New River,
Virginia, Geomorphology, 72(1-4), 54-72, doi:10.1016/j.geomorph 2005.05.002.

Whipple, K. X. (2004), Bedrock rivers and the geomorphology of active orogens, Annu. Rev. Earth Planet. Sci., 32, 151-185, doi:10.1146/annurev.earth.32.101802.120356.

Whipple, K. X., and G. E. Tucker (1999), Dynamics of the stream-power river incision model: Implications for height limits of mountain ranges, landscape response timescales, and research needs, J. Geophys. Res., 104(B8), 17,661-17,674, doi:10.1029/1999JB900120.

Whipple, K. X., G. S. Hancock, and R. S. Anderson (2000), River incision into bedrock: Mechanics and relative efficacy of plucking, abrasion, and cavitation, Geol. Soc. Am. Bull., 112(3), 490-503, doi:10.1130/00167606(2000)112<490:RIIBMA $>2.0$. CO;2.

Whittaker, A. C., P. A. Cowie, M. Attal, G. E. Tucker, and G. P. Roberts (2007a), Bedrock channel adjustment to tectonic forcing: Implications for predicting river incision rates, Geology, 35(2), 103-106, doi:10.1130/ G23106A.1

Whittaker, A. C., P. A. Cowie, M. Attal, G. E. Tucker, and G. P. Roberts (2007b), Contrasting transient and steady-state rivers crossing active normal faults: New field observations from the Central Apennines, Italy, Basin Res., 19(4), 529-556, doi:10.1111/j.1365-2117.2007.00337x.

Willett, S. D. (1999), Orogeny and orography: The effects of erosion on the structure of mountain belts, J. Geophys. Res., 104(B12), 28,957-28,981, doi:10.1029/1999JB900248.

Willis, C. M., and G. B. Griggs (2003), Reductions in fluvial sediment discharge by coastal dams in California and implications for beach sustainability, J. Geol., 111(2), 167-182, doi:10.1086/345922.

Wobus, C., K. X. Whipple, E. Kirby, N. Snyder, J. Johnson, K. Spyropolou, B. Crosby, and D. Sheehan (2006a), Tectonics from topography: Procedures, promise, and pitfalls, Spec. Pap. Geol. Soc. Am., 398, 55-74.

Wobus, C. W., G. E. Tucker, and R. S. Anderson (2006b), Self-formed bedrock channels, Geophys. Res. Lett., 33, L18408, doi:10.1029/ 2006GL027182.

Wobus, C. W., J. W. Kean, G. E. Tucker, and R. S. Anderson (2008), Modeling the evolution of channel shape: Balancing computational efficiency with hydraulic fidelity, J. Geophys. Res., 113, F02004, doi:10.1029/ 2007JF000914

Wohl, E., and H. Achyuthan (2002), Substrate influences on incised-channel morphology, J. Geol., 110(1), 115-120, doi:10.1086/324207.

Wohl, E., and G. C. L. David (2008), Consistency of scaling relations among bedrock and alluvial channels, J. Geophys. Res., 113, F04013, doi: $10.1029 / 2008$ JF000989

Wohl, E. E., and H. Ikeda (1998), Patterns of bedrock channel erosion on the Boso Peninsula, Japan, J. Geol., 106(3), 331-346, doi:10.1086/ 516026.

Wong, M., and G. Parker (2006), Reanalysis and correction of bed-load relation of Meyer-Peter and Müller using their own database, J. Hydraul. Eng., 132(11), 1159-1168, doi:10.1061/(ASCE)0733-9429(2006)132:11 (1159).

Yanites, B. J., G. E. Tucker, K. Mueller, Y. G. Chen, T. Wilcox, and S. Y. Huang (2010), Incision and channel morphology across active structures in the Peikang River, central Taiwan: Implications for the importance of channel width, Geol. Soc. Am. Bull., 122(7-8), 1192-1208, doi:10.1130/ B30035.1.

G. E. Tucker, CIRES, University of Colorado at Boulder, Box 216 UCB, Boulder, CO 80309-0216, USA.

B. J. Yanites, Department of Geological Sciences, University of Michigan, 3024 C. C. Little Bldg., 1100 N. University Ave., Ann Arbor, MI 48109-1005, USA. (yanites@umich.edu) 